\title{
MicroRNAs As Potential Targets for Abiotic Stress Tolerance in Plants
}

\author{
Varsha Shriram ${ }^{1}$, Vinay Kumar ${ }^{2 *}$, Rachayya M. Devarumath ${ }^{3}$, Tushar S. Khare ${ }^{2}$ and \\ Shabir H. Wani ${ }^{4}$ \\ ${ }^{1}$ Department of Botany, Prof. Ramkrishna More Arts, Commerce and Science College, Savitribai Phule Pune University, \\ Pune, India, ${ }^{2}$ Department of Biotechnology, Modern College of Arts, Science and Commerce, Savitribai Phule Pune \\ University, Pune, India, ${ }^{3}$ Molecular Biology and Genetic Engineering Section, Vasantdada Sugar Institute, Pune, India, \\ ${ }^{4}$ Division of Genetics and Plant Breeding, Faculty of Agriculture WADURA, Sher-e-Kashmir University of Agricultural Sciences \\ and Technology, Kashmir, India
}

\section{OPEN ACCESS}

Edited by:

Nokwanda Makunga, Stellenbosch University, South Africa

Reviewed by:

Biswapriya Biswavas Misra,

University of Florida, USA Taras P. Pasternak,

Institute of Biology II, Germany

${ }^{*}$ Correspondence:

Vinay Kumar

vinaymalik123@gmail.com

Specialty section

This article was submitted to

Plant Biotechnology,

a section of the journal

Frontiers in Plant Science

Received: 21 March 2016

Accepted: 25 May 2016

Published: 14 June 2016

Citation:

Shriram V, Kumar V, Devarumath RM

Khare TS and Wani SH (2016)

MicroRNAs As Potential Targets for Abiotic Stress Tolerance in Plants.

Front. Plant Sci. 7:817.

doi: 10.3389/fpls.2016.00817
The microRNAs (miRNAs) are small (20-24 nt) sized, non-coding, single stranded riboregulator RNAs abundant in higher organisms. Recent findings have established that plants assign miRNAs as critical post-transcriptional regulators of gene expression in sequence-specific manner to respond to numerous abiotic stresses they face during their growth cycle. These small RNAs regulate gene expression via translational inhibition. Usually, stress induced miRNAs downregulate their target mRNAs, whereas, their downregulation leads to accumulation and function of positive regulators. In the past decade, investigations were mainly aimed to identify plant miRNAs, responsive to individual or multiple environmental factors, profiling their expression patterns and recognizing their roles in stress responses and tolerance. Altered expressions of miRNAs implicated in plant growth and development have been reported in several plant species subjected to abiotic stress conditions such as drought, salinity, extreme temperatures, nutrient deprivation, and heavy metals. These findings indicate that miRNAs may hold the key as potential targets for genetic manipulations to engineer abiotic stress tolerance in crop plants. This review is aimed to provide recent updates on plant miRNAs, their biogenesis and functions, target prediction and identification, computational tools and databases available for plant miRNAs, and their roles in abiotic stress-responses and adaptive mechanisms in major crop plants. Besides, the recent case studies for overexpressing the selected miRNAs for miRNA-mediated enhanced abiotic stress tolerance of transgenic plants have been discussed.

Keywords: abiotic stress, microRNA, post-transcriptional regulation, stress-responses, transgenics

\section{INTRODUCTION}

Plants being sessile organisms, persistently face adverse environmental perturbations termed as abiotic stresses, most important being drought, soil salinity, extreme temperatures, and heavy metals. Abiotic stresses have become a major challenge due to their widespread nature and the devastating impacts on plant growth, yields and the quality of plant produce. However, plants have developed intricate mechanisms for sensing and responding to environmental changes (Wani et al., 2016).

To turn on protective mechanisms, plants trigger a network of genetic regulations including altered expression of large proportion of genes by transcriptional and/or translational regulations 
(Ku et al., 2015). Plants up-regulate the protective genes while down-regulating the negative regulators. Several protein-coding genes have been recognized in recent years for controlling plant responses to abiotic stresses; however, our knowledge on the regulatory mechanisms involved in this response are still limited and necessitates transformative tools to adapt crops to harsh environments (Zhang and Wang, 2015). These posttranscriptional regulations are pivotal for plants to restore and re-establish their cellular homeostasis during and recovery from stress phases, respectively (Sunkar et al., 2012).

Recent research indicates that plants assign miRNAs as critical post-transcriptional gene-expression regulators to attenuate plant growth and development under stress conditions, though how this is achieved at molecular levels is yet to be understood with greater details. The miRNAs represent a widespread class of small (20-24 nt) endogenous RNAs (Zhang, 2015) and regulate the gene expression via directing mRNA cleavage, translational repression, chromatin remodeling, and/or DNA methylation. Usually, stress-upregulated miRNAs down-regulate their target mRNAs, whereas, their suppression leads to accumulation and function of positive regulators (Chinnusamy et al., 2007). Several studies have confirmed that abiotic stress conditions induce aberrant expressions of miRNAs in plants. High throughput sequencing and computational approaches have been used in recent year for identifying a large number of stress-related miRNAs. These findings indicate that miRNAs might serve as potential targets for genetic manipulations to engineer abiotic stress tolerance in plants. We summarize herein recent updates on plant miRNAs, their biogenesis, target-genes, and their regulatory roles in abiotic stress-responses and adaptive mechanisms deciphered in major crop plants. Besides, the overexpression of selected miRNAs for miRNA-mediated plant stress tolerance has also been discussed. We have also tried to shed light upon recent successes, current challenges and future directions in this field.

\section{PLANT miRNAs: TINY SIZE MAJOR ROLES}

Production of abiotic stress tolerant crops necessitates better understanding of gene-regulation mechanisms employed by the plants in response to these environmental cues. Research focused on deciphering post-transcriptional regulations by non-protein coding small RNAs that consists blocking of specific messenger RNAs (mRNAs) or affecting epigenetic modifications at the transcriptional level has gained unprecedented attention. The family members of these small ribonucleotide sequences are represented by RNA species differing from each other on the basis of their size, biogenesis, mode of action, and/or regulatory role (Mittal et al., 2016). MiRNAs are abundant in plants and are attributed for major roles in post-transcriptional regulations through base-pairing with complementary mRNA targets, particularly transcription factors (TFs) (Li and Zhang, 2016). In plants, post transcriptional gene regulation involves miRNAs, generated by Dicer-like 1 (DCL1) from miRNA precursors that are transcribed from miRNA genes (Mangrauthia et al., 2013). Plant miRNAs along with TFs constitutes two major families of gene regulators, and these molecules are suggested to share similar regulatory logistics besides participating in cooperative activities in gene regulatory networks (Lin et al., 2012).

The discovery of miRNA genes in Caenorhabditis elegans (Lee et al., 1993) has been followed by a sharp increase in identification of more and more plant miRNA families, making them a research hotspot (Cao et al. 2014; Supplementary Table S1 and Supplementary Figure S1). A steady progress in investigations involving miRNAs has led to a better understanding of transcriptional and post-transcriptional level gene-regulatory mechanisms in plants (Sunkar et al., 2012; Zhang, 2015). These tiny-sized non-coding molecules derived from stemloop structures are regarded as ubiquitous repressors of geneexpression as they fine-tune the target gene expression and degrade and/or inhibit protein production in higher eukaryotes (Akdogan et al., 2015). It exemplifies the emerging view that miRNAs rival the proteins in regulatory importance (Mishra et al., 2015). Nevertheless, this regulation is highly critical for all biological processes as well as stress-response and acclimatization, thus has a big impact on life processes of plants as indicated by several recent investigations (Zhang and Wang, 2015; Li and Zhang, 2016). MiRNAs control the gene expression via causing epigenetic changes besides controlling targets at posttranscriptional level (Khraiwesh et al., 2010; Wu et al., 2010).

Recent findings affirmed that miRNAs play an array of important roles in plant growth, development and metabolism along with their involvement in abiotic stress and pathogen responses (Yang C. et al., 2013; Xie et al., 2015). MiRNAs have been reported as key regulators of plant root development architecture via targeting AUXIN RESPONSE TRANSCRIPTION FACTOR (ARFs) (Khan et al., 2011). On similar lines, in a recent study, Ripoll et al. (2015) observed miRNA-regulated fruit growth in Arabidopsis. Besides, plant miRNAs are also known to target genes involved in processes such as sulfur assimilation and ubiquitin-dependent protein degradation (Bonnet et al., 2004). Since vegetative parts are important in crop plants for harvesting reasons, therefore control of plant apical dominance and vegetative growth is significant. There is increasing evidence that miRNAs play crucial role in leaf-development, apical dominance and biomass production, and targeting specific miRNAs is proving a novel and potent strategy for improving plant growth, biomass and crop yield (Zhang and Wang, 2015).

Computational predictions coupled with experimental approaches have led to the conclusion that many TFs including MYB are indeed miRNA targets. Deep sequencing has confirmed the critical roles miRNAs play in cotton ovule and/or fiber development (Xie et al., 2015). They regulate key genes involved in the floral induction and flower formation processes such as transition phases from juvenile to adult, initiation of floralcompetence and flower development (Hong and Jackson, 2015). Fruit and seed development held a distinct place in plant propagation and harvesting for defining crop yields, therefore, the roles played by the miRNAs in development of fruits and seeds is of great interest. Itaya et al. (2007) identified a large number of species-specific miRNAs from tomato (Solanum lycopersicon) and hypothesized their significant roles in fruit 
development. Further, tissue-specific expression of numerous miRNAs was reported by Moxon et al. (2008) and the authors proposed miRNA-regulated fleshy fruit development and ripening in S. lycopersicon. A number of miRNAs have been identified for targeting metabolic pathways of grain-filing and nutrient-biosynthesis including carbohydrate and protein metabolism, cellular transport and signal transduction besides phytohormone signaling (Meng et al., 2013; Peng et al., 2013; Zhang and Wang, 2015). MiRNAs have been attributed for vital functions in somatic embryogenesis in cotton (Gossypium hirsutum) as revealed by the high-throughput and degradome sequencing (Yang X. et al., 2013). Interestingly, deciphering the regulatory roles of miRNAs is not confined only to primary metabolites. Recently, it was revealed that certain miRNAs target transcripts related to secondary metabolism as well (Boke et al., 2015; Bulgakov and Avramenko, 2015) and of these miR156, miR163, miR393, and miR828 have been ascribed as interesting tools for regulating secondary metabolism in Arabidopsis.

\section{PLANT miRNAS: THEIR BIOGENESIS, TARGETS AND MODE OF ACTION}

Much research, ever since the first report on plant miRNAs in 2002 (Reinhart et al., 2002) has resulted in a considerable gain in our understanding of their origin. Owing to the ubiquitousness and diversity of plant miRNAs, it is apparent that most, if not all, biological processes in plants at some point involve the action of one or more miRNAs (Voinnet, 2009). Plant miRNAs share many similarities with their animal counterparts as revealed by the recent genetic and biochemical studies focused on deciphering their origin, biogenesis and modes of action. These small but fundamental molecules are synthesized from primary (pri)-miRNA transcripts, which are in turn transcribed usually by RNA pol II or pol III from the nuclear-encoded miRNA (MIR) genes. The pri-miRNA transcripts form double stranded stem-loop (imperfectly paired hairpin) structured precursor RNAs (pre-miRNA). In plants, apparently RNA-binding protein DAWDLE (DDL) stabilizes the pri-miRNAs for their conversion to stem-loop pre-miRNAs in D-bodies. This reaction requires a concentrated action and physical interaction of SERRATE (SE, a C2H2-zinc finger protein), a ds-RNA binding protein HYPONASTIC LEAVES1 (HYL1), DCL-1 and nuclear capbinding complex (CBC) (Fang and Spector, 2007; Gregory et al., 2008; Laubinger et al., 2008; Voinnet, 2009). The premiRNA hairpin precursor then gets converted into 20-22 nt miRNA::miRNA* duplex, where miRNA acts as guide-strand whereas miRNA* as degraded strand by the actions of DCL1, HYL1, and SE. This duplex then undergoes methylation at $3^{\prime}$ terminus by HUA ENHANCER1 (HEN1) to protect them against degradation by small RNA degrading exonuclease, SDN. The pre-miRNAs or the mature miRNAs are then exported from nucleus to the cytoplasm by the plant exportin protein HASTY (Chaves et al., 2015). One strand of the duplex in cytoplasm gets unwound into a single stranded mature-miRNA which then gets incorporated into an ARGONAUTE protein, and directs RNA induced silencing complex (RISC) binding to cognate target transcripts through sequence complementarities (Voinnet, 2009; Khraiwesh et al., 2010, 2012).

The successful identification and binding of miRNA-AGO complex with specific mRNA-targets negatively regulate their expression via mRNA cleavage, decay, and/or posttranscriptional repression (Jones-Rhoades et al., 2006). Though there is clear evidence that the level as well as positions of complementarities between the mRNA targets and miRNAs defines the target selectivity, however, there is possibility of involvement of other factors as well (Wang et al., 2015). Since all the miRNAs regulate plant growth and development as well as stress-responses via targeting individual protein-coding genes, therefore identification of these mRNA targets is the first and most important step in elucidating the functions of miRNAs (Zhang and Wang, 2015). Once incorporated in RISC as discussed above, usually the mature miRNA regulate the expression of target genes via three mechanisms. It induces mRNA-slicing of specific target-gene and it is a main pathway of miRNA action in plants (He et al., 2014), whereas second pathway include the inhibition of translation of functional proteins through combining target gene's mRNA and third one incorporates silencing of multi-genes at transcriptional level via chromosomal isochromatin (He et al., 2014). Owing to the fact that plant miRNAs represents the non-coding regions of the genes, they act as an independent transcription unit. TFs are their major targets and have therefore critical roles in hormonal signal transduction, cellular metabolism, organ differentiation, floral patterning and reproduction, as well as in nutrient homeostasis and plant responses to stresses (Sun, 2012; Hong and Jackson, 2015; Tripathi et al., 2015).

\section{IDENTIFICATION AND TARGET PREDICTION OF PLANT MIRNAS: COMPUTATIONAL TOOLS AND RESOURCES}

To identify miRNAs in plants, both experimental as well as computational approaches have been used so far. Identification of miRNAs in plants started in early 2000s with direct-cloning approaches (Llave et al., 2002; Reinhart et al., 2002). Though, it was not easy to identify large number of miRNAs, owing to their multiple occurrences, small size and methylation status. But advancement in cloning methodologies and computational algorithms resulted in a rapid increase in number of miRNAs identified in plants in last few years (Tripathi et al., 2015). In recent past, the advent of high throughput/deep sequencing has really helped in an exponential growth in the number of plant miRNAs, not only identified but also functionally annotated (Jagadeeswaran et al., 2010; Rosewick et al., 2013). This has resulted into establishment of biological databases to act as archives of miRNA-sequences and annotation such as miRBase (Tripathi et al., 2015).

Several computational tools and databases have been developed in recent times to identify and predict the targets of miRNAs using traditional nucleotide databases as well as datasets 
generated through deep-sequencing approaches, a detailed list is provided in Table 1.

The miRBase (http://www.mirbase.org/) represents a comprehensive database with searchable online repository of published miRNA sequences and associated annotation. This database was started in 2002 with its first release included just 5 miRNAs from one plant species (Arabidopsis thaliana), whereas its latest version (Release 21, June 2014) contains 28,645 entries representing hairpin precursor miRNAs, expressing 35,828 mature miRNA products in 223 species including 73 plant species with 7057 miRNA loci between them (Kozomara and Griffiths-Jones, 2014).

miRNEST represents a wide-ranging database of animal, plant, and virus miRNAs (Szczesniak et al., 2011, http:// mirnest.amu.edu.pl). It provides miRNA data on the basis of computational predictions and high-throughput sequencing. It's current (miRNEST 2.0) version contains miRNAs from 22 viruses and $>270$ plant species. Interestingly, this database also includes degradome data of 2041 entries (as on March 16, 2016).

Plant miRNA database (PMRD, http://bioinformatics.cau. edu.cn/PMRD/) provides information about plant-miRNA sequences as well as their targets (Zhang et al., 2010). It contains the sequence information, secondary structure, target genes, expression profiles and a genome browser. PMRD contains more than 8400 miRNA entries from $>120$ model plants as well as major crops including Arabidopsis thaliana, rice (Oryza sativa), wheat (Triticum aestivum), soybean (Glyciene max), and maize (Zea mays), besides providing predicted target-genes and interaction-site in the database. An updated version of PMRD has been launched as PNRD (Plant Non-coding RNA Database) with greater number of entries and plant species as well as broad spectrum RNA types (Yi et al., 2015). There are total 25,739 entries of non-coding RNA (ncRNA) including lncRNAs, tRNA, rRNA, tasiRNA, snRNA, and snoRNA from around 150 plant species, especially food crops. It offers various search and analysis tools for the user such as ncRNA keyword search, for example ID search, target search, and toolkits for predicting online novel miRNAs and for calculating coding potential along with the availability of BLAST tools (http://structuralbiology.cau.edu.cn/ PNRD/index.php).

PMTED (Plant miRNA Target Expression Database, http:// pmted.agrinome.org/) is a plant-specific miRNA database, useful to study miRNA functions by inferring their target gene expression profiles among the large amount of existing microarray data. It contains tools to search miRNA targets, retrieve expression data and the user can find out differentially expressed genes (Sun et al., 2013).

The TAPIR (target prediction for plant miRNAs) webserver (http://bioinformatics.psb.ugent.be/webtools/tapir/) predicts targets for plant miRNAs, with two available modes, the first "Fast" mode using the FASTA search engine while the second "Precise" mode using the RNA-hybrid search engine (Bonnet et al., 2010).

miRPlant is an integrated tool for identification of plant miRNA from RNA sequencing data (An et al., 2014, http: //www.australianprostatecentre.org/research/software/mirplant). miRPlant works on the strategies specifically developed to identify hairpin excision regions and hairpin structure filtering for plants. Interestingly, it does not need third party tools, rather, it uses a graphic user interface for input and output of the data, and the display of recognized miRNA with RNAseq reads is done with the help of a hairpin diagram.

PlantMirnaT developed by Rhee et al. (2015) is a miRNA and mRNA integrated analysis system via utilizing the sequencing data effectively. Its major features include a short read mapping tool, and an algorithm which takes into consideration the miRNA expression and distribution in target mRNAs (Rhee et al., 2015; https://sites.google.com/site/biohealthinformaticslab/resources).

miTRATA (miRNA-Truncation and Tailing Analysis) is a web-tool for truncation and tailing analysis of miRNA, and utilizes the miRBase (var. 21) and useful to analyze $3^{\prime}$ modifications of miRNAs (Patel et al. 2016). In recent years, thorough miRNA biogenesis has revealed more complex features and secondary structures of their precursors. Consequently, Evers et al. (2015) proposed a freely available public access tool "miRA" (https://github.com/mhuttner/miRA) for identification of plant-miRNA precursors, which is adaptable to heterogeneous and complex precursor populations. Interestingly, Meng et al. (2016) developed a tool to predict the functions of plant miRNAs on the basis of their functional similarity network through application of transductive multi-label classification. Transposable elements (TEs) have been recognized for their prominent roles in determining non-coding regions including miRNAs of the genomes (Gim et al., 2014). In order to develop a plant TE related miRNA database (PlanTE-MIR DB) was proposed very recently by R Lorenzetti et al. (2016). The authors identified more than 150 miRNAs overlapping TEs in 10 plant genomes. This pubic database is hosted at http://bioinfo-tool.cp. utfpr.edu.br/plantemirdb/.

It is noteworthy to mention here that in spite of numerous computational tools to identify plant-miRNAs and their target prediction, there is a lack of curated databases of stress related miRNAs. Zhang et al. (2013) advocated for a need to construct a cohesive database system for data deposit and further applications of plant abiotic stress related miRNAs and accordingly developed PASmiR, which allows the users to retrieve miRNA-stress regulatory entries by keyword-search such as plant species and type of stress (Zhang et al., 2013). Similarly, Remita et al. (2015) proposed a web-based server/database "WMP" dedicated to wheat miRNAs, particularly stress-responsive miRNAs and is available at: http://wheat.bioinfo.uqam.ca.

\section{miRNAs INVOLVED IN PLANT ABIOTIC-STRESS RESPONSES}

Through adaptive evolution processes, plants have developed incredible abilities to respond and adapt to challenging external conditions. The cellular and molecular responses of plants to these abiotic stresses are intricate and received great attention of plant breeders and biotechnologists in recent past to decipher them. Plants deploy multitude abiotic stress responsive mechanisms involving regulation of expression of stress-responsive genes to sense and respond to external stimuli. 
TABLE 1 | A summarized list of major tools available for plant miRNAs, their target identification/prediction and repositories.

\begin{tabular}{|c|c|c|c|}
\hline $\begin{array}{l}\text { Name of the } \\
\text { database/resource/ } \\
\text { repository/tool }\end{array}$ & Description & Web link & References \\
\hline TAPIR & Target prediction for Plant miRs & http://bioinformatics.psb.ugent.be/webtools/tapir/ & Bonnet et al., 2010 \\
\hline miRTarBase & $\begin{array}{l}\text { The experimentally validated miR-target interactions } \\
\text { database }\end{array}$ & http://mirtarbase.mbc.nctu.edu.tw/index.php & Hsu et al., 2011 \\
\hline PMRD & Plant miRNA Database & http://bioinformatics.cau.edu.cn/PMRD/ & Zhang et al., 2010 \\
\hline miRanalyzer & $\begin{array}{l}\text { miR detection and analysis tool for next-generation } \\
\text { sequencing experiments }\end{array}$ & http://bioinfo5.ugr.es/miRanalyzer/miRanalyzer.php & Hackenberg et al., 2011 \\
\hline PmiRKB & $\begin{array}{l}\text { Plant miR Knowledge Base. } \\
\text { Four major functional modules, SNPs, Pri-miRs, } \\
\text { MiR-Tar and Self-reg, are provided }\end{array}$ & http://bis.zju.edu.cn/pmirkb/ & Meng et al., 2011 \\
\hline miRDeep-P & $\begin{array}{l}\text { A computational tool for analyzing the } \\
\text { miRtranscriptome in plants }\end{array}$ & http://faculty.virginia.edu/lilab/miRDP/ & Yang and Li, 2011 \\
\hline C-mii & A tool for plant miR and target identification & http://www.biotec.or.th/isl/c-mii & Numnark et al., 2012 \\
\hline Semirna & Searching for plant miRNAs using target sequences & http://www.bioinfocabd.upo.es/semirna/ & $\begin{array}{l}\text { Muñoz-Mérida et al., } \\
2012\end{array}$ \\
\hline mirTool & $\begin{array}{l}\text { A comprehensive web server providing detailed } \\
\text { annotation information for known miRs and predicting } \\
\text { novel miRs that have not been characterized before }\end{array}$ & http://centre.bioinformatics.zj.cn/mirtools/ & Wu et al., 2013 \\
\hline PASmiR & $\begin{array}{l}\text { A literature-curated database for miR molecular } \\
\text { regulation in plant response to abiotic stress }\end{array}$ & & Zhang et al., 2013 \\
\hline miRBase & $\begin{array}{l}\text { Searchable database of published miR sequences and } \\
\text { annotation }\end{array}$ & http://www.mirbase.org & $\begin{array}{l}\text { Kozomara and } \\
\text { Griffiths-Jones, } 2014\end{array}$ \\
\hline miRPlant & $\begin{array}{l}\text { An Integrated Tool for Identification of Plant MiR from } \\
\text { RNA Sequencing Data }\end{array}$ & $\begin{array}{l}\text { http://www.australianprostatecentre.org/research/ } \\
\text { software/mirplant }\end{array}$ & An et al. (2014) \\
\hline MTide & $\begin{array}{l}\text { An integrated tool for the identification of miR-target } \\
\text { interaction in plants }\end{array}$ & http://bis.zju.edu.cn/MTide/ & Zhang et al., 2014b \\
\hline PNRD & It is an updated version of PMRD & http://structuralbiology.cau.edu.cn/PNRD/index.php & Yi et al., 2015 \\
\hline PlantMirnaT & A miRNA-mRNA integrated analysis system & $\begin{array}{l}\text { https://sites.google.com/site/biohealthinformaticslab/ } \\
\text { resources }\end{array}$ & Rhee et al., 2015 \\
\hline miRA & $\begin{array}{l}\text { Plant miRNA identification tool especially for organisms } \\
\text { without existing miRNA annotation. It is also useful for } \\
\text { identifying species-specific miRNAs }\end{array}$ & https://github.com/mhuttner/miRA & Evers et al., 2015 \\
\hline miPEPs & $\begin{array}{l}\text { MiRNAs Encode Peptides is a tool for functional } \\
\text { analysis of plant miRNA family members }\end{array}$ & & Couzigou et al., 2015 \\
\hline sRNAtoolbox & $\begin{array}{l}\text { A set of tools for expression profiling and analysis of } \\
\text { sRNA bench results }\end{array}$ & http://bioinfo5.ugr.es/srnatoolbox & Rueda et al., 2015 \\
\hline miRge & $\begin{array}{l}\text { A fast multiplexed method of processing } \\
\text { sRNA-sequence data to determine miRNA entropy } \\
\text { and identify differential production of miRNA isomiRs }\end{array}$ & http://atlas.pathology.jhu.edu/baras/miRge.html. & Baras et al., 2015 \\
\hline BioVLAB-MMIA-NGS & $\begin{array}{l}\text { MiRNA and mRNA integrated analysis using } \\
\text { high-throughput sequencing data coupled with } \\
\text { bioinformatics tools. }\end{array}$ & http://epigenomics.snu.ac.kr/biovlab_mmia_ngs/ & Chae et al., 2015 \\
\hline DMD & $\begin{array}{l}\text { A dietary miRNA database from } 15 \text { dietary plant and } \\
\text { animal species }\end{array}$ & http://sbbi.unl.edu/dmd/ & Chiang et al., 2015 \\
\hline WMP & $\begin{array}{l}\text { Database for abiotic stress responsive miRNAs in } \\
\text { wheat }\end{array}$ & http://wheat.bioinfo.uqam.ca & Remita et al., 2015 \\
\hline miTRATA & A tool for miRNA truncation and tailing analysis & https://wasabi.dbi.udel.edu/ apps/ta/ & Patel et al., 2016 \\
\hline MFSN & $\begin{array}{l}\text { A tool for prediction of plant miRNA functions based on } \\
\text { functional similarity network (MFSN) through } \\
\text { application of transductive multi-label classification } \\
\text { (TRAM) to the MFSN }\end{array}$ & & Meng et al., 2016 \\
\hline PlanTE-MIR & $\begin{array}{l}\text { Database for transposable element-related plant } \\
\text { microRNAs }\end{array}$ & http://bioinfo-tool.cp.utfpr.edu.br/plantemirdb/ & R Lorenzetti et al., 2016 \\
\hline P-SAMS & $\begin{array}{l}\text { A Plant Small RNA Maker Site (P-SAMS) is a web tool } \\
\text { for artificial miRNAs and synthetic trans-acting small } \\
\text { interfering RNAs }\end{array}$ & http://p-sams.carringtonlab.org & Fahlgren et al., 2016 \\
\hline
\end{tabular}


Investigations in recent times have shown that different abiotic stress conditions induce aberrant expression of thousands of protein-coding genes in various plant species (Kumar et al., 2009; Zeller et al., 2009; Turan and Tripathy, 2013; Khare et al., 2015). Many of these stress-induced, often individual, genes for example proline biosynthetic pathway gene P5CS in rice (Kumar et al., 2010), methionine sulfoxide reductase gene (MSRB7) in Arabidopsis (Lee et al., 2014) and transcription factor TaERF3 in wheat (Rong et al., 2014) were overexpressed to produce respective transgenic plants to confer enhanced tolerance against singular abiotic stress. However, the regulatory mechanisms of these protein-coding genes are largely unknown (Sun, 2012), in this regard, the miRNAs may prove extremely important in deciphering these gene-regulatory mechanisms and the stress-responses. Though, large numbers of miRNA-families are conserved in flowering plants, however, recent updates indicated that miRNAs may be species-, physiological stage or event-, organ or tissue-, and stress-specific (Valdes-Lopez et al., 2010; Sun, 2012).

Several miRNAs have been recognized as abiotic stressregulated in important crops and/or model plants under soil salinity (Gao et al., 2011), nutrient deficiency (Liang et al., 2015), UV-B radiation (Casadevall et al., 2013), heat (Goswami et al., 2014), and metal stress (Yang and Chen, 2013; Gupta et al., 2014). However, this stress-regulated miRNA expression does not essentially confirm that the miRNA is involved in plant's adaptation to stress conditions. Zhang et al. (2013) observed differential expression of as many as 1062 miRNAs in 41 plant species under 35 different types of abiotic stresses. Table 2 summarizes recent data on the altered miRNA expression in major crop plants in response to abiotic stresses.

\section{Drought and Salinity Stress}

Owing to the widespread challenges these two stress-factors put on plant growth and yield, drought, and salinity stresses have received maximum attention of plant scientists to study their deleterious effects and decrypting the responsive-mechanisms adopted by the plants. Over the past two decades, researchers investigated and identified number of genes to improve stress tolerance of transgenics overexpressing those genes. However, on one hand the resultant transgenic plants showed inadequate improvement largely because the complex genetic interactions and on the other hand their regulation underlying plant stress tolerance are not completely understood (Sunkar et al., 2012). Non-coding RNAs including miRNAs however are turning to be a potent platform to understand and decode stress-responsive transcriptional and post-transcription gene regulations in plants.

A number of drought stress-responsive miRNAs were identified via screening of small RNAs library isolated from Arabidopsis (Liu et al., 2008), rice (Zhou et al., 2010), and sugarcane (Gentile et al., 2015) and the count is ever increasing. Liu et al. (2008) evidenced a total of 14 stress-inducible miRNAs in Arabidopsis, out of them 10 were $\mathrm{NaCl}$-regulated, 4 droughtregulated and 10 were cold $\left(4^{\circ} \mathrm{C}\right)$-regulated, and miR168, $m i R 171$, and $m i R 396$ (with TFs as predicted targets) responded to all of the stresses.
In rice, Zhao et al. (2007) reported that $m i R 169 g$ and miR393 are strongly upregulated and transiently induced, respectively by drought. In another study, Zhou et al. (2010) used microarray approach for identify and analyze miRNAs in drought stressed rice at developmental stages ranging from tillering to inflorescence formation. Overall, drought conditions induced differential expressions of 30 miRNAs, out of which 19 were newly reported drought-regulated miRNAs from Arabidopsis. Sixteen miRNAs (miR156, miR159, miR168, miR170, miR171, miR172, miR319, miR396, miR397, miR408, miR529, miR896, miR1030, miR1035, miR1050, miR1088, and miR1126) were downregulated by drought stress while it induced the overexpression of 14 miRNAs (miR159, miR169, miR171, miR319, miR395, miR474, miR845, miR851, miR854, miR896, miR901, miR903, miR1026, and miR1125). Notably, miR171, miR319, and miR896 were identified in both (overexpressed and repressed) groups (Zhou et al., 2010). Predicted targets of the differentially regulated miRNAs were largely TFs (Zhou et al., 2010). Similarly, drought stress induced expression was observed in 438 miRNAs against 205 under controlled conditions in Triticum turgidum leaf and root tissues, and 13 miRNAs were differentially regulated by drought conditions (Kantar et al., 2010). Aberrant miRNA expression was observed in soybean cultivars subjected to drought conditions, with upregulation of miR166-5p, miR169-3p, miR1513c, miR397ab, and miRseq13 in sensitive cultivars but downregulation in their tolerant counterparts (Kulcheski et al., 2011).

Recently in sugarcane, the expression pattern of miRNA was observed to be dependent on the species, type of stress, tissue (seedlings, leaves, spikelets, and root) growth condition (field, greenhouse, hydroponic culture system). MiR396 and miR171 were differentially expressed in the most of the cases (Gentile et al., 2015). Interestingly, overexpression of osa-miR393 resulted into enhanced salt tolerance, suggesting their regulatory role in salinity tolerance in Arabidopsis (Gao et al., 2011). In similar vein, Sun et al. (2015) identified 49 known and 22 novel salt stress-responsive miRNAs in radish (Raphanus sativus) and interestingly the target prediction analysis revealed the implication of the target genes in signaling, regulating ionhomeostasis besides modulating the decreased plant growth under salt stress.

\section{Extreme Temperatures}

Plants often face extreme temperatures due to geographical conditions and seasonal variations, which negatively affects the plant growth and productivity and plants adjust their gene expression patterns at post-transcriptional levels in response to these inconstant external temperatures. Numerous chilling or heat responsive miRNAs have been detected in plant species (Cao et al., 2014). Wheat seedlings of heat tolerant and susceptible cultivars when exposed to heat stress $\left(40^{\circ} \mathrm{C}\right)$ exhibited differential miRNA gene expression with increased expression in many of them, where expression was suppressed in few under heat stress (Xin et al., 2011). Eighteen coldresponsive miRNAs were identified by $\mathrm{Lv}$ et al. (2010) in rice with most of them being downregulated by the cold stress $\left(4^{\circ} \mathrm{C}\right)$ and the authors hypothesized the miRNAs as 
TABLE 2 | Differential expression patterns of miRNAs reported under different abiotic stresses (S- salinity; D- drought; HT- high temperature; C- cold; Cd- cadmium; As- arsenic) in major crops- Oryza sativa, Triticum aestivum, Saccharum sp., Glycine max, and Hordeum vulgare.

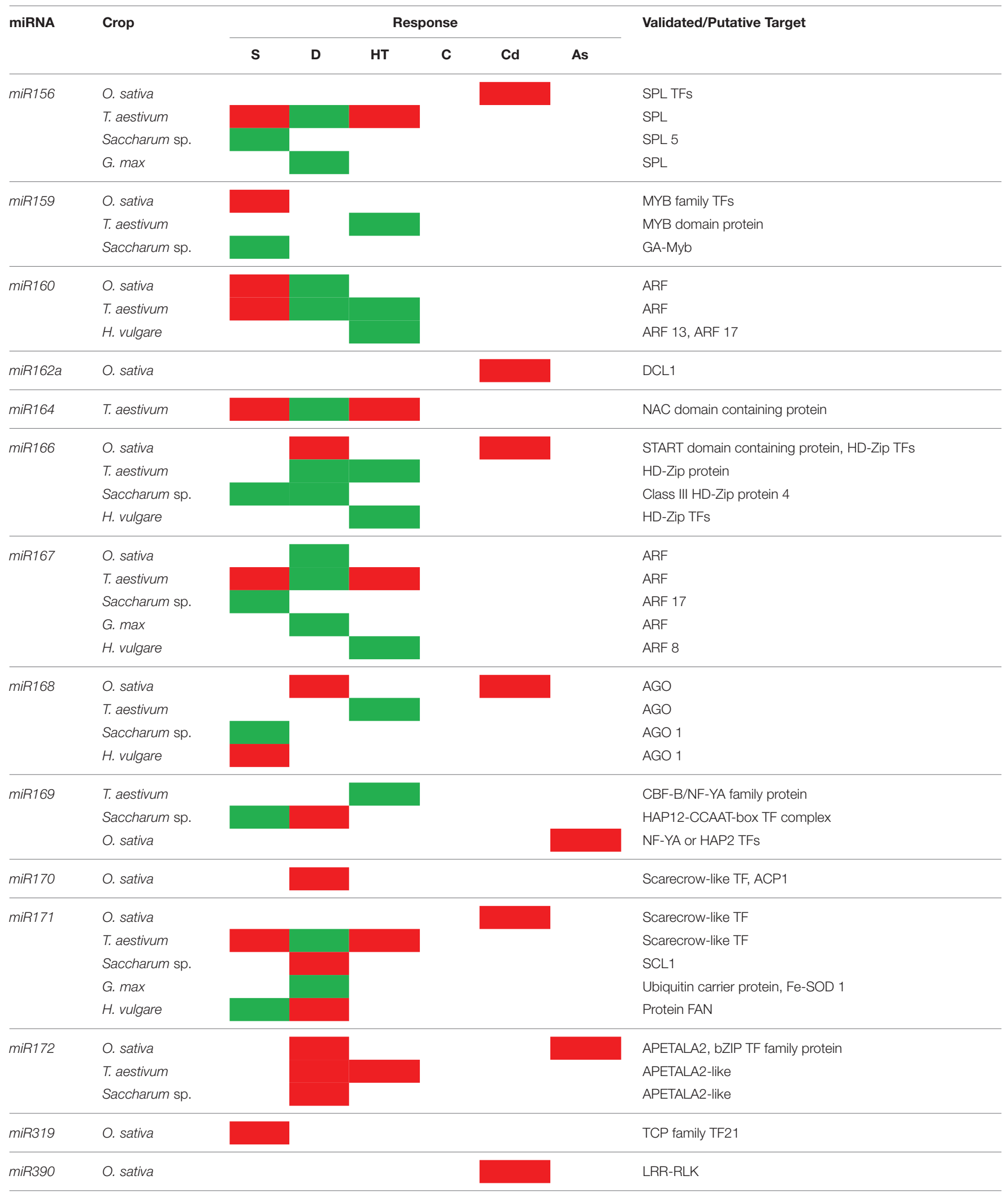


TABLE 2 | Continued

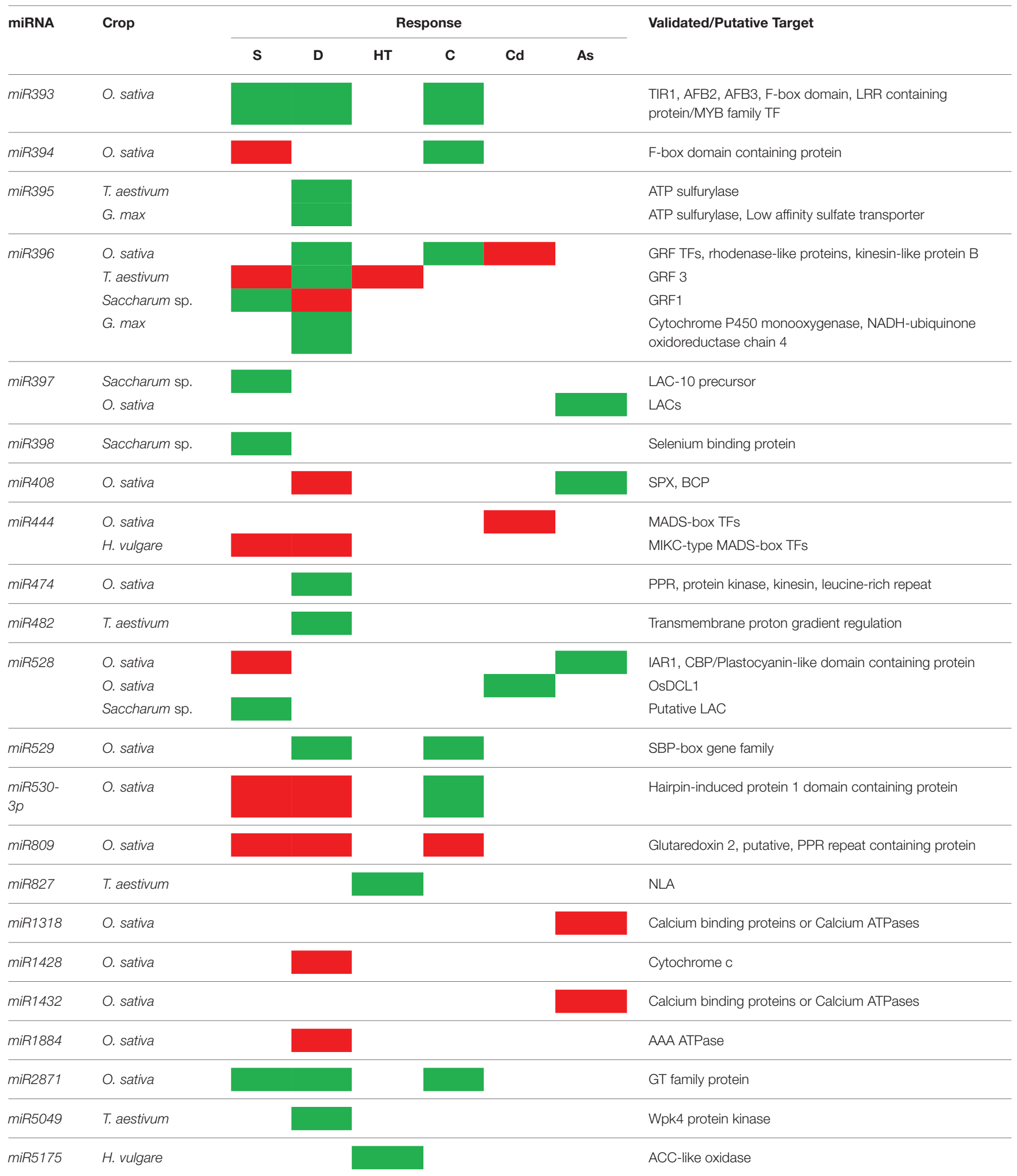

In the table differential expression pattern of miRNAs under different abiotic stress environments (salt, drought, high temperature, cold, cadmium, and arsenic) was marked as induced (green box) or repressed (red box) expression. References- Oryza sativa: Ding et al. (2011), Barrera-Figueroa et al. (2012), Zhou et al. (2010), Xia et al. (2012), Liu and Zhang (2012); Triticum aestivum: Xin et al. (2010), Pandey et al. (2014), Akdogan et al. (2015); Saccharam: Bottino et al. (2013), Gentile et al. (2015); Glycine max: Li et al. (2011); Hordium vulgare: Deng et al. (2015), Hackenberg et al. (2015), Kruszka et al. (2014). 
ubiquitous regulators in rice. On the other hand, cold stress brought a sharp increase in the expression of $m i R 812 q$ in rice plants at the beginning of reproductive phase (Jeong et al., 2011). These observations hold merit, since $m i R 812 q$ originates from a sequence-diverged region, has unique sequence, and unlike other family members, is cold-responsive (Jeong et al., 2011; Jeong and Green, 2013). Cold stress induced miR812q targets CIPK10 and downregulates the later, interestingly, CIPK transcripts are known abiotic stress tolerance mediators in calcium dependent CBL-CIPK signaling pathway (Jeong and Green, 2013).

Such differential expression may be due to species-specific role of miRNAs in cold response (Jeong and Green, 2013). In a recent study by Zhang et al. (2014a), high-throughput sequencing analyses revealed cold stress-induced upregulation of 31 and downregulation of 43 miRNAs in tea (Camellia sinensis) plants and authors identified a large number of target genes using degradome sequencing. Functional analysis of miRNA targets reaffirmed their critical roles in stress response. Similarly, Cao et al. (2014) constructed small-RNA and degradome libraries from wild tomato (Solanum habrochaites), and out of these, 192 miRNAs showed increased expression, while expression was decreased in 205 miRNAs. Besides, authors also predicted the miRNA targets and few of the targets were validated using qRT-PCR. Further, most of the target genes were reported to have positive role in chilling response as revealed by their functional analysis via regulating the expression anti-stress proteins and antioxidants (Cao et al., 2014).

\section{Hypoxia and Oxidative Stress}

Oxygen is extremely important for aerobic organisms including plants. Hypoxia or low-oxygen stress usually results from but not limited to the water logging conditions in the rhizospheric environments of plants. It eventually leads to diminished oxygen availability and thus severely affecting the mitochondrial respiration (Agarwal and Grover, 2006). However, hypoxia also holds significance in signaling. It induces a metabolic shift from aerobic respiration to anaerobic fermentation and significant changes in transcriptome (Moldovan et al., 2010). Recent studies suggested a number of miRNAs as hypoxia-responsive and advocate them to be critical posttranscriptional modulators (Licausi et al., 2011; Zhai et al., 2013). In Arabidopsis roots, Moldovan et al. (2010) reported enhanced expression levels of miR156g, miR157d, miR158a, $m i R 159 a, m i R 172 a, b, m i R 391$, and $m i R 775$ by low oxygen stress.

In Arabidopsis, Sunkar et al. (2006) revealed repression of miR398 and the upregulation of superoxide dismutase (SOD) proteins under oxidative stress. A study of $\mathrm{H}_{2} \mathrm{O}_{2}$-regulated miRNAs from rice seedlings indicated that expression of some miRNAs is regulated in response to oxidative stress; results revealed that out of seven $\mathrm{H}_{2} \mathrm{O}_{2}$-responsive miRNAs i.e., miRNAs that were expressed differentially in $\mathrm{H}_{2} \mathrm{O}_{2}$-treated and control samples; $m i R 169, m i R 397, m i R 827$, and $m i R 1425$ were upregulated while miR528 was downregulated by $\mathrm{H}_{2} \mathrm{O}_{2}$ treatments (Li et al., 2010).

\section{Heavy Metals (HMs)}

Though heavy metals naturally occur in earth's crust, but anthropogenic and industrial activities has led to severe HM pollution in vast areas under cultivation. HM toxicity is one of the major abiotic stresses leading to hazardous effects via altering the physiological and metabolic processes that negatively affects growth, development and productivity of crops (Rascio and Navari-Izzo, 2011; Gupta et al., 2014). HMs can be categorized into two groups, essential and non-essential HMs. Copper $(\mathrm{Cu})$, iron $(\mathrm{Fe})$, zinc $(\mathrm{Zn})$, and manganese $(\mathrm{Mn})$ which at low concentrations plays vital roles in enzymatic and biochemical reactions in plant cell, however are toxic at higher concentrations (Rascio and Navari-Izzo, 2011; Gielen et al., 2012). Whereas nonessential metals consists of cadmium (Cd), aluminum (Al), and mercury $(\mathrm{Hg})$ and are toxic to plants even at low concentrations (Gielen et al., 2012). Though cobalt (Co) was historically not considered as vital for plant growth and development, however, it is now classified as essential micronutrient. Co plays significant roles in growth and development of plant buds, leaf-discs stems and coleoptile, besides assisting in $\mathrm{CO}_{2}$ absorption by the plants (Diez, 2014). The HM entry to human food-chain through contaminated crops is a serious human health threat (Gupta et al., 2014). Recent investigations have established miRNAmediated transcriptional and post-transcriptional regulations of gene expression via base-pairing with their target mRNAs in plants subjected to HM-stress (Yang and Chen, 2013).

\section{Cd-Toxicity}

Cd accumulation by plants results into chlorosis, wilting, growth reduction and cell death, damage to proteins and induces oxidative stress (Zhao et al., 2012). Cd affects crop productivity and its exposure predominantly through food contamination pose serious risks to human health (Rizwan et al., 2016). Steady progress has been made in recent past in investigating the molecular mechanisms involved in $\mathrm{Cd}$ toxicity and tolerance/adaptive mechanisms in plants. Aberrant miRNA expression in stressed plant cells and tissues indicated involvement of miRNAs in Cd-responses.

Huang et al. (2010) documented elevated expression of bnamiR393 in leaves, bna-miR156a, bna-miR167a/c in roots and leaves, bna-miR164b and $b n a-m i R 394 a / b / c$ in all tissues of rapeseed (Brassica napus) upon Cd exposure with concomitant downregulation of miR160. The authors in an attempt to predict the targets generated transgenic $B$. napus lines by overexpressing miR395 and confirmed its targets to be sulfate transporters (particularly SULTR2;1) and ATP sufurylases (APS) (Huang et al., 2010). SULTR2;1 is vital for its role in sulfate remobilization from mature to younger leaves while APS catalyzes the first step in the sulfur assimilation (Liang et al., 2010). Similarly, Zhou et al. (2012a) reported Cd induced differential expression of numerous conserved and non-conserved miRNAs in B. napus roots. Using deep-sequencing analysis, authors tried to understand how $\mathrm{Cd}$ regulates genome-wide regulation of miRNA expression and their targets, in all 84 miRNAs including conserved and nonconserved families were identified with most of the miRNAs exhibiting differential expression in shoots/roots under Cd stress (Zhou et al., 2012a). In rice, using microarray assay, Ding et al. 
(2011) identified 19 Cd-responsive miRNAs from rice seedlings, and their targets were predicted as transcription factors and stress related proteins. In an attempt to decipher the Cd-responsive miRNAs and their mediated gene regulatory networks at the transcriptome level, Xu et al. (2013) constructed small RNA libraries from radish (Raphanus sativus) with or without exposed to Cd stress. They identified 15 known and 8 novel miRNA families with notable differential expression in Cd-stressed plants and their targets were then predicted using degradome analysis. Authors postulated the target genes of Cd-responsive miRNAs as phytochelatin-synthase-1, and iron and $\mathrm{ABC}$ transporter proteins (Xu et al., 2013).

\section{Hg-Toxicity}

$\mathrm{Hg}$ is a highly toxic metal and its ionic form $\left(\mathrm{Hg}^{2+}\right)$ is most prevalent in soil and bioavailable form for plants which are readily taken up through root and aerial part of the plants. It causes toxicity response such as stunted growth, loss of cell shape, vascular abnormality, reduced chlorophyll content and reactive oxygen species (ROS) accumulation (Chen and Yang, 2012). Differential miRNA expressions have been reported as a response to $\mathrm{Hg}$ exposure in various plant species, for instance, Zhou et al. (2012b) through deep sequencing approach observed that numerous conserved as well as nonconserved miRNAs were differentially expressed in barrel-clover (Medicago truncatula) seedlings subjected to Hg stress. A total of 130 targets for 58 known miRNA families comprising both conserved as well as non-conserved, besides, 37 targets for novel M. truncatula-specific candidate miRNAs were identified using degradome sequencing (Zhou et al., 2012b). Authors attributed the differential expression of identified miRNAs and their targets to Hg stress.

An unfortunate consequence of abiotic stresses is the oxidative burst mediated through the excessive ROS generation in plant tissues and cells (Khare et al., 2015). Plants deploy antioxidative armory with enzymatic and non-enzymatic components to detoxify or scavenge these ROS in a systematic way (Khare et al., 2015). Recent reports confirm the role of miRNAs as post-transcriptional regulators of metal induced oxidative stress and responsive antioxidation. It is exemplified by $\mathrm{Hg}$ induced enhanced activity of superoxide dismutase (SOD) in alfalfa (Medicago sativa, Zhou et al., 2008). Further, the overexpression of miR398-resistant transcript of CSD2 (Cu/ZnSOD 2) resulted into more CSD2 transcripts and enhanced heavy metal tolerance in transgenic Arabidopsis over their nontransformed counterparts (Sunkar et al., 2006), suggesting the apparent involvement of miR398 in Hg-induced responses.

\section{Mn-Toxicity}

Manganese acts as inorganic catalyst, while $\mathrm{Mn}$ and $\mathrm{Fe}$ are important components for many enzymatic reactions. Comparably lesser research has been carried out to identify the Mn-toxicity regulated miRNAs, their targets and detailed post-transcriptional regulatory mechanisms in plants in response to Mn stress (Valdes-Lopez et al., 2010; Gupta et al., 2014). Valdes-Lopez et al. (2010) used miRNA macroarray hybridization approach coupled with qRT-PCR to identify Mn-responsive
miRNAs in common bean (Phaselous vulgaris) and a total of 37 miRNAs displayed differential expression under abiotic stresses including $\mathrm{Mn}$. Out of these, eleven miRNAs were induced whereas another eleven were inhibited under $\mathrm{Mn}$ stress. $m i R 1508, m i R 1515, m i R 1510 / 2110$, and $m i R 1532$ were characterized as Mn-responsive and their targets were predicted as calcium-dependent protein kinase, heat shock proteins, nucleotide-binding site leucine rich repeat resistance like proteins and receptor kinase protein, respectively (Valdes-Lopez et al., 2010).

\section{As-Toxicity}

Arsenic is a class-I carcinogen, widely distributed metalloid present in the earth's crust and enforces severe threats to human health via entering the food chain through contaminated food crops (Srivastava et al., 2011). Investigations have shown that arsenite toxicity in plant tissues leads to reduced photosynthesis rate, perturbed carbohydrate metabolism, besides, generation of ROS, and lipid peroxidation (Jha and Dubey, 2004; Requejo and Tena, 2005). However, little is known about the miRNAmediated post-transcriptional regulatory mechanisms involved in As responses and tolerance in plants. Therefore, it is interesting to investigate and understand regulatory roles miRNAs play in response to As-stress in plants. In rice, Yu et al. (2012) identified 36 new miRNAs responsive to As and they are involved regulating gene expression in transportation, signaling and metabolism, these finding leads to jasomonic acid (JA) and lipid metabolism in response to As-stress. In addition, Liu and Zhang (2012) reported 67 As-responsive miRNAs from indica rice roots and showed that miR408, miR528, and miR397b had increased expression, however $m i R 1316$ and $m i R 390$ were repressed under As-stress. Since the role of JA in As stress perception is established (Srivastava et al., 2009), a few miRNAs have been identified to affect JA biosynthesis via targeting the transcription factor involved therein (Gupta et al., 2014), for instance, Srivastava et al. (2012) has reported that $m i R 319$ has been found to be responsive to As stress. This indicates the critical roles of plant miRNAs in regulating JA biosynthesis and which might in turn be involved in metal toxicity responses in plants.

\section{Al-Toxicity}

$\mathrm{Al}$ is a major toxicity factor, negatively affecting the crop production on $30-40 \%$ of the world's arable land. It binds with $\mathrm{COOH}$ and $\mathrm{PO}_{4}$ groups present on the root cell wall, which leads to structural changes, inhibition of cell wall expansion and diminished root growth (Ma et al., 2004). This reduces the uptake of minerals nutrient and water. It also affects physiological processes like callose deposition, imbalance cytoplasmic $\mathrm{Ca}^{2+}$ and induce oxidative stress (Silva, 2012). In recent years, role of miRNA using high-throughput genome sequencing, Chen et al. (2012) reported altered expression of 23 miRNAs in $M$. truncatula seedlings subjected to Al-stress. Subsequently using same methodology Zeng et al. (2012) identified 30 miRNAs in Al-treated soybean, and interestingly, in this study miR396 and $m i R 390$ were upregulated unlike earlier observations by Chen et al. (2012), indicating species-specific nature of these miRNAs. 


\section{Nutrient Homeostasis}

Mineral nutrients are essential for plant growth, development and crop yield formation. Plants acquire them from their soils and translocate them in cellular compartments. Nutrient homeostasis in plants needs to be maintained for optimal growth and yields. There is increasing evidence to establish critical roles that miRNAs play in nutrient metabolism, besides in maintaining the nutrient homeostasis via regulated-expression of genes involved in uptake and translocation of mineral nutrients in plants (Kehr, 2013; Paul et al., 2015).

Nitrogen $(\mathrm{N})$, Phosphorus $(\mathrm{P})$, potassium (K), and sulfur (S) are vital macronutrients needed for optimal plant growth and development, while various micronutrients such as iron $(\mathrm{Fe})$ and copper $(\mathrm{Cu})$ serve as cofactors of metabolic enzymes and protein complexes in the electron transport chain. Their acquisition, assimilation and metabolism are regulated in plants and deprivation of nutrients affects the production and quality of crop plants. Recently, several novel miRNA were reported for nutrient homeostasis (Fischer et al., 2013; Kehr, 2013; Paul et al., 2015).

Plants respond to phosphate deprivation largely through transcriptional regulation and miRNAs are considered to play pivotal role in phosphate homeostasis (Kant et al., 2011). Several miRNAs have been attributed for the differential regulation of phosphate related gene expression in Arabidopsis (Lundmark et al., 2010), rice (Hu et al., 2011), wheat (Zhao et al., 2013), barley (Hackenberg et al., 2013), and maize (Pei et al., 2013). Interestingly, overexpression of osa-miR827 (which targets SPX-MFS protein family members) resulted into perturbed $\mathrm{P}$ homeostasis and mobilization in rice leaves, over-accumulation of $\mathrm{Pi}$ in older leaves indicating the regulatory role of miRNA in $\mathrm{P}$ metabolism (Wang et al., 2012).

Nitrogen being an essential constituent of nucleic acids, protein and chlorophyll is highly significant for plant growth and survival and its deficiency exerts serious growth retardations (Paul et al., 2015). There are recent reports of miRNA mediated regulation of plant growth and metabolism under N-deficiency. Liang et al. (2012) recorded differential expression of $\mathrm{N}$ deficiency responsive miRNAs in Arabidopsis. N-starvation induced the expression levels of miR160, miR780, miR826, $m i R 842$, and $m i R 846$, while expressions were repressed in case of miR169, miR171, miR395, miR397, miR398, miR399, miR408, miR827, and miR857. Interestingly, authors concluded that many of the N-responsive miRNAs were involved in cross-talks between responses to multiple nutrients including $\mathrm{N}, \mathrm{P}, \mathrm{S}$, and $\mathrm{Cu}$. Authors identified a novel N-deficiency induced miR826 which targeted AOP gene encoding 2-oxoglutarate-dependent dioxygenase involved in glucosinolate biosynthesis (Liang et al., 2012). Similarly, global miRNA expression profiling was carried out in rice cultivars with contrasting tolerance abilities against $\mathrm{N}$-deprivation (Nischal et al., 2012). Results revealed differential expressions of 32 miRNAs and the predicted target genes included TFs, proteins involved in metabolic processes as well as stress-proteins (Nischal et al., 2012). All these reports establish key roles played by miRNAs in low-N tolerance in crop plants.
Sulfur is essential for plant growth and physiological functioning. Plant roots uptake $S$ in the form of sulfate, which should be reduced to sulfide before it is further metabolized. Sulfur starvation results into physiological imbalances, reduced plant growth, loss of plasticity against environmental stresses and pathogenic attacks, and overall yield reductions. MiR395 represents a conserved plant miRNA which targets a low-affinity sulfate transporter and ATP sulfurylases (APS) (Jagadeeswaran et al., 2014). S-starvation induced expression of $m i R 395$ is well known in Arabidopsis (Kawashima et al., 2009; Jeong et al., 2011; Jagadeeswaran et al., 2014). S-deficiency-specific induction of miR395 has been reported to be controlled by SLIM1 (SULFUR LIMITATION 1) (Kawashima et al., 2009). The same group reported that miR395 in association with SLIM fine tune the expression of APS under S-starvation (Kawashima et al., 2011). Jeong et al. (2011) reported that rice plants overexpressing miR395 displayed $\mathrm{S}$ deficiency symptoms. In an interesting study, Jagadeeswaran et al. (2014) reported the upregulation of miR395 in Arabidopsis seedlings in response to arsenateor $\mathrm{Cu}^{2+}$-induced oxidative stress. Authors evidenced that the application of glutathione repressed miR395 induction in Sstarved plants and they concluded the apparent involvement of redox signaling in induced-expression of miR395 in S-deficient Arabidopsis seedlings (Jagadeeswaran et al., 2014).

Copper is essential for plants particularly for photosynthesis. Most common $\mathrm{Cu}$-proteins, the plastocyanin and $\mathrm{Cu} / \mathrm{Zn}-\mathrm{SOD}$ are found in chloroplasts, interestingly though; $\mathrm{Cu} / \mathrm{Zn}-\mathrm{SOD}$ can be replaced by $\mathrm{Fe}-\mathrm{SOD}$ under limited $\mathrm{Cu}$ availability (Abdel-Ghany and Pilon, 2008). Abdel-Ghany and Pilon (2008) reported that Arabidopsis plants accumulated miR397, miR408, and miR857 under low $\mathrm{Cu}$ availability and authors concluded miRNA-mediated regulation as critical mechanism to regulate non-essential $\mathrm{Cu}$-proteins. The low- $\mathrm{Cu}$ induced downregulation of $\mathrm{Cu} / \mathrm{Zn}-\mathrm{SOD}$ involves miRNAs (miR398) interferences. MiR398 is a conserved plant miRNA and as discussed earlier, it target and downregulates CSD1 and CSD2 via inhibiting their mRNA translation. Further, Beauclair et al. (2010) reported that $\mathrm{Cu}$-starvation induces miR398 also downregulates CCS1 $(\mathrm{Cu}$ chaperones for SOD1, which is essential for synthesizing mature $\mathrm{Cu} / \mathrm{Zn}$-SOD in Arabidopsis). Contrarily, some miRNA families ( $m i R 397, m i R 408$, and miR857) get induced under low amount of $\mathrm{Cu}$ and eventually repress the expression of laccase and plastocyanin genes (Paul et al., 2015). In a recent study, Jin et al. (2015) identified several $\mathrm{Cu}$-stress responsive miRNAs in tree peony (Paeonia ostii), with 12 conserved and 18 new. The sequence homology search for target prediction revealed multiple targets of many miRNAs, and more than one third targets were involved in biological process (Jin et al., 2015). Authors attributed strong $\mathrm{Cu}$ stress tolerance abilities of $P$. ostii to miRNA-mediated gene regulatory mechanisms.

Other minerals, vital for plant growth and development, include $\mathrm{Mn}, \mathrm{Fe}$ and $\mathrm{Zn}$. Fe and $\mathrm{Zn}$ acts as cofactors for numerous key metabolic enzymes (Forieri et al., 2013) and their bioavailability largely depends on their uptake, transport and allocation. Waters et al. (2012) reported downregulation of $m i R 397 a, m i R 398 a$, and $m i R 398 b / c$ by Fe-deficiency, suggesting 
their possible involvement in plant adaptation to $\mathrm{Fe}$ stress. Interestingly, authors proposed that the $\mathrm{Cu}$ accumulation, miRNA-regulation and concomitant contrasting expression patterns of $\mathrm{Fe}$ and $\mathrm{Cu}-\mathrm{SOD}$ genes are coordinated responses to Fe limitation (Waters et al., 2012). Further, depleted supply of Zn resulted into elevated miR398 expression coupled with repressed expression of CSD, while downregulation of $m i R 398$ resulted in comparatively steady levels of CSD expression in Sorghum leaves, indicating miRNAs as critical regulators of plant-responses to $\mathrm{Zn}$ shortage (Li et al., 2013). In another noteworthy investigation, Marín-González and Suárez-López (2012) demonstrated that miRNAs are involved in nutrient transport and inter-cellular and long-distance signaling in plants.

\section{UV-Radiation}

Elevated levels of UV-B radiation as a consequence of ozone-layer depletion negatively affect plant growth and development mainly via ROS-mediated oxidative burst (Kruszka et al., 2012).

In a recent study, Wang et al. (2013) isolated a novel wheat Tae-miR6000, and confirmed its expression diversity after UV-B treatments. Additionally, they identified miR156, miR159, $m i R 164, m i R 167 a, m i R 171$, and $m i R 395$ as UV-B responsive. Of these, $m i R 159, m i R 167 a$, and $m i R 171$ were significantly upregulated and the remaining three miRNAs were downregulated, at different time points after UV-B treatment.

\section{TARGETING miRNAs FOR DEVELOPING ABIOTIC STRESS TOLERANT TRANSGENIC PLANTS}

Several transgenic strategies are employed in crop improvement investigations with primary objective of improved crop yield and quality (Privalle et al., 2012). The principal concentration of these improvement strategies has been on the abiotic stress and herbicide or pest resistant genes (Kumar et al., 2010; Buiatti et al., 2013). Among all the strategies, miRNA based genetic modification seems most promising since miRNA regulates gene expression at transcriptional or post-transcriptional levels. Several methods can be employed for miRNA manipulations including desired overexpression/repression of stress-responsive miRNAs and/or their target mRNAs, miRNA-resistant target genes, target-mimics and artificial miRNAs (amiRNAs, Zhou and Luo, 2013). Various studies have confirmed the vital roles of miRNAs in multiple developmental as well as signaling pathways in plants. Aberrant expression patterns of these small molecules, which might be stress-, genotype-, tissue-, miRNA-specific, induced by abiotic environment proposes their potential use as target for genetic improvement (Zhang, 2015). Latest advancements in genomics have provided the scientific society with genome wide high throughput sequence data of many important crop species which is a rich source of information about potential candidate transgenes, of which miRNA have become progressively demandable due to their important regulatory role in various phases of plant life cycle (Sun, 2012; Zhou and Luo, 2013; Zhang and Wang, 2016). The list of transgenic plants produced recently via altering the miRNA expression for improving plant tolerance to abiotic stresses is presented in Table 3.

Information regarding RNA mediated stress regulatory networks offers an innovative path for improved stress tolerance on genetic level. Recent reports have revealed that manipulation of miRNA arbitrated gene regulations can help to engineer plants for enhanced abiotic stress tolerance (Zhang and Wang, 2016). Due to their central role in intricate gene regulatory network, miRNAs may prove potent targets for plant improvement, with superior tolerance to abiotic stresses (Zhang and Wang, 2015). Either altered tolerance or sensitivity against various abiotic stresses as equated to their wild types is obtained via miRNA-overexpression in transgenic plants (Table 3). These are some of the promising examples of miRNA grounded manipulations for plant tolerance enhancement with respect to harsh environmental conditions.

The $m i R 156$ is the first documented miRNA in plants, vital for plant development, and works as important signaling molecule for on-time flowering. For moderately longer period it also helps to maintain juvenile state of plants. MiR156 overexpressing rice plants showed reduced cold tolerance (Cui et al., 2015). The miR172, which regulates the expression of AP2-like TFs, is recognized as flowering time controller as well as abiotic stress responder. Overexpression of gma-miR172 in Arabidopsis revealed the enhanced water deficit and salt tolerance (Li et al., 2016). Several studies have suggested that miR319 is concomitant with multiple abiotic stresses which show upregulation during many of the abiotic stress conditions (Zhou et al., 2010). Overexpression of osa-miR319a in creeping bentgrass (Agrostis stolonifera) significantly improved the salt and drought tolerance of transgenic plants (Zhou et al., 2013). Transgenic rice overexpressing miR319 showed enhanced cold tolerance. Recent reports advocated the vital role of $m i R 390$ in plants against abiotic stress (Ding et al., 2016). In rice, miR390 encodes OsSRK, (O. sativa stress-responsive leucine-rich repeat receptor-like kinase) which plays crucial role in plant development, resistance against the disease and in response to several biotic and abiotic stress environments. The miR394 is one of the evolutionary conserved miRNAs which shows aberrant expression pattern under abiotic stress. Circumscribed water loss is observed during leaf transpiration in transgenic Arabidopsis plants overexpressing gma-miR394 which eventually improved the drought tolerance (Ni et al., 2012). On similar basis, Song et al. (2016) demonstrated that transgenic Arabidopsis overexpressing miR394 as well as $L C R$ (LEAF CURLING RESPONSIVENESS, a target of miR394) loss of function $l c r$ mutants exhibited enhanced cold stress tolerance, indicating the involvement of miR394 and its target gene LCR in low-temperature responses of plants (Song et al., 2016).

\section{CONCLUSION AND PERSPECTIVES}

Since the first report of plant miRNAs in early 2000s, remarkable growth has been witnessed in the studies aimed on plant miRNAs. Ever growing evidence reaffirms that these tiny molecules play pivotal roles in plant growth, development and their responses to environmental cues. In last 10 years, large number of 
TABLE 3 | Overexpression of single common stress-responsive miRNA for conferring abiotic stress tolerance in model and crop plants.

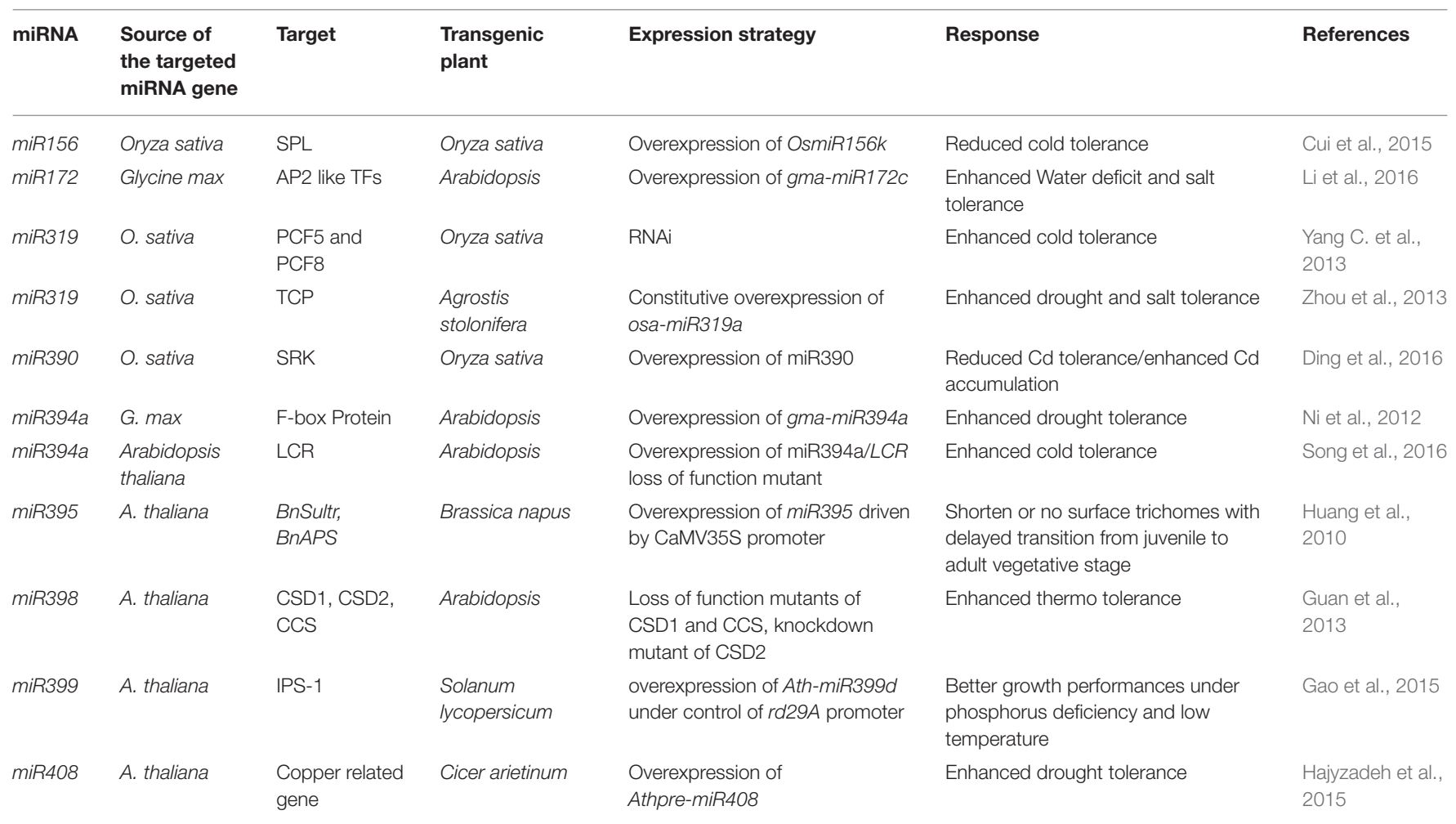

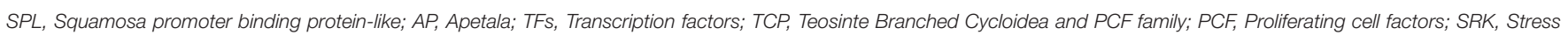

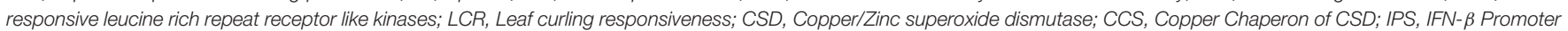
stimulator; BnSultr, Brassica napus sulfate transporters; BnAPS, B. napus ATP sulfurylases.

conserved as well as non-conserved stress-responsive plantmiRNAs have been identified from major crop and model plant species and this process is fastened with advent of high throughput or deep sequencing technologies. High throughput sequencing tools have helped researchers for genome-wide miRNA expression profiling under important abiotic stresses. Various computational tools and public web-resources have been developed to facilitate the identification, expression profiling and target predictions of stress-responsive miRNAs, besides archiving them. Technological developments have taken place for effective and quick identification of multiple-miRNAs targets including degradome sequencing. However, it has its limitation in identifying targets for miRNAs, particularly the ones, those target gene expression through translation repression and therefore necessitates better alternatives. However, there is a need for functional characterization of miRNAs as regulators of plant responses to singular as well as multiple abiotic stresses. Similarly, as pointed out in some recent reviews (Zhang, 2015; Zhang and Wang, 2015), the amiRNAs may prove to be important for functional studies.

Owing to the critical roles in post-transcriptional regulation of gene-expression in-response-to abiotic stresses and resultant growth attenuation, miRNAs represents themselves as potent targets to engineer abiotic stress tolerance in major crops through transgenic technologies. Therefore, miRNAs represents potential targets for conferring abiotic stress tolerance in plants through their induced altered expression; however, there is a long way to go for effective use of this strategy for producing abiotic stress tolerant plants.

\section{AUTHOR CONTRIBUTIONS}

VK, VS, TSK, RMD, and SHW drafted the manuscript. VS, VK and TSK prepared the tables and revised the manuscript. All the authors made substantial contribution to the work and approved it for publication.

\section{ACKNOWLEDGMENTS}

The research in VK's lab is supported through funds from Science and Engineering Research Board (SERB), Government of India (grant number SR/FT/LS-93/2011), University Grants Commission [grant number 41-521/2012 (SR)] and Savitribai Phule Pune University, Pune research grant.

\section{SUPPLEMENTARY MATERIAL}

The Supplementary Material for this article can be found online at: http://journal.frontiersin.org/article/10.3389/fpls.2016. 00817 


\section{REFERENCES}

Abdel-Ghany, S. E., and Pilon, M. (2008). microRNA-mediated systemic downregulation of copper protein expression in response to low copper availability in Arabidopsis. J. Biol. Chem. 283, 15932-15945. doi: 10.1074/jbc.M801406200

Agarwal, S., and Grover, A. (2006). Molecular biology, biotechnology and genomics of flooding-associated low $\mathrm{O}_{2}$ stress response in plants. Crit. Rev. Plant Sci. 25, 1-21. doi: 10.1080/07352680500365232

Akdogan, G., Tufekci, E. D., Uranbey, S., and Unver, T. (2015). miRNAbased drought regulation in wheat. Funct. Integr. Genomics 16, 221-233. doi: 10.1007/s10142-015-0452-1

An, J., Lai, J., Sajjanhar, A., Lehman, M. L., and Nelson, C. C. (2014). miRPlant: an integrated tool for identification of plant miRNA from RNA sequencing data. BMC Bioinformatics 15:275. doi: 10.1186/1471-2105-15-275

Baras, A. S., Mitchell, C. J., Myers, J. R., Gupta, S., Weng, L. C., Ashton, J. M., et al. (2015). miRge - A multiplexed method of processing small RNAseq data to determine microRNA entropy. PLoS ONE 10:e0143066. doi: 10.1371/journal.pone.0143066

Barrera-Figueroa, B. E., Gao, L., Wu, Z., Zhou, X., Zhu, J., Jin, H., et al. (2012). High throughput sequencing reveals novel and abiotic stress-regulated microRNAs in the inflorescences of rice. BMC Plant Biol. 12:132. doi: 10.1186/1471-2229$12-132$

Beauclair, L., Yu, A., and Bouché, N. (2010). microRNA-directed cleavage and translational repression of the copper chaperone for superoxide dismutase mRNA in Arabidopsis. Plant J. 62, 454-462. doi: 10.1111/j.1365313X.2010.04162.X

Boke, H., Ozhuner, E., Turktas, M., Parmaksiz, I., Ozcan, S., and Unver, T. (2015). Regulation of the alkaloid biosynthesis by miRNA in opium poppy. Plant Biotechnol. J. 13, 409-420. doi: 10.1111/pbi.12346

Bonnet, E., He, Y., Billiau, K., and Van de Peer, Y. (2010). TAPIR, a web server for the prediction of plant microRNA targets, including target mimics. Bioinformatics 26, 1566-1568. doi: 10.1093/bioinformatics/btq233

Bonnet, E., Wuyts, J., Rouz,é, P., and Van de Peer, Y. (2004). Detection of 91 potential conserved plant microRNAs in Arabidopsis thaliana and Oryza sativa identifies important target genes. Proc. Natl. Acad. Sci. U.S.A. 101, 11511-11516. doi: 10.1073/pnas.0404025101

Bottino, M. C., Rosario, S., Grativol, C., Thiebaut, F., Rojas, C. A., Farrineli, L., et al. (2013). High-throughput sequencing of small RNA transcriptome reveals salt stress regulated microRNAs in sugarcane. PLoS ONE 8:e59423. doi: 10.1371/journal.pone.0059423

Buiatti, M., Christou, P., and Pastore, G. (2013). The application of GMOs in agriculture and in food production for a better nutrition: two different scientific points of view. Genes Nutr. 8, 255-270. doi: 10.1007/s12263-012-0316-4

Bulgakov, V. P., and Avramenko, T. V. (2015). New opportunities for the regulation of secondary metabolism in plants: focus on microRNAs. Biotechnol. Lett. 37, 1719-1727. doi: 10.1007/s10529-015-1863-8

Cao, X., Wu, Z., Jiang, F., Zhou, R., and Yang, Z. (2014). Identification of chilling stress-responsive tomato microRNAs and their target genes by highthroughput sequencing and degradome analysis. BMC Genomics. 15:1130. doi: 10.1186/1471-2164-15-1130

Casadevall, R., Rodriguez, R. E., Debernardi, J. M., Palatnik, J. F., and Casati, P. (2013). Repression of growth regulating factors by the microRNA396 inhibits cell proliferation by UV-B radiation in Arabidopsis leaves. Plant Cell 25, 3570-3583. doi: 10.1105/tpc.113.117473

Chae, H., Rhee, S., Nephew, K. P., and Kim, S. (2015). BioVLAB-MMIA-NGS: microRNA-mRNA integrated analysis using high throughput sequencing data. Bioinformatics 31, 265-267. doi: 10.1093/bioinformatics/btu614

Chaves, S. S., Fernandes-Brum, C. N., Silva, G. F. F., Ferrara-Barbosa, B. C., Paiva, L. V., Nogueira, F. T. S., et al. (2015). New Insights on coffea miRNAs: features and evolutionary conservation. Appl. Biochem. Biotechnol. 177, 879-908. doi: $10.1007 /$ s12010-015-1785-x

Chen, J., and Yang, Z. M. (2012). Mercury toxicity, molecular response and tolerance in higher plants. Biometals 25, 847-857. doi: 10.1007/s10534-0129560-8

Chen, L., Wang, T., Zhao, M., Tian, Q., and Zhang, W. H. (2012). Identification of aluminum-responsive microRNAs in Medicago truncatula by genome-wide high-throughput sequencing. Planta 235, 375-386. doi: 10.1007/s00425-0111514-9
Chiang, K., Shu, J., Zempleni, J., and Cui, J. (2015). Dietary microRNA database (DMD): an archive database and analytic tool for food-borne microRNAs. PLoS ONE 10:e128089. doi: 10.1371/journal.pone.0128089

Chinnusamy, V., Zhu, J., Zhou, T., and Zhu, J. K. (2007). "Small RNAs: big role in abiotic stress tolerance of plants". in Advances in Molecular Breeding Toward Drought and Salt Tolerant Crops, eds M. A. Jenks, P. M. Hasegawa, and S. M. Jain (Dordrecht: Springer), 223-260.

Couzigou, J.-M., Lauressergues, D., Bécard, G., and Combier, J. P. (2015). miRNAencoded peptides (miPEPs): a new tool to analyze the roles of miRNAs in plant biology. RNA Biol. 12, 1178-1180. doi: 10.1080/15476286.2015.10 94601

Cui, N., Sun, X., Sun, M., Jia, B., Duanmu, H., Lv, D., et al. (2015). Overexpression of OsmiR156k leads to reduced tolerance to cold stress in rice (Oryza Sativa). Mol. Breed. 35, 214. doi: 10.1007/s11032-015-0402-6

Deng, P., Wang, L., Cui, L., Feng, K., Liu, F., Du, X., et al. (2015). Global identification of microRNAs and their targets in barley under salinity stress. PLoS ONE 10:e0137990. doi: 10.1371/journal.pone.0137990

Diez, R. (2014). Cobalt's Role in Plants. Available online at: http://dyna-gro-blog. com/cobalts-role-in-plants/

Ding, Y., Chen, Z., and Zhu, C. (2011). Microarray-based analysis of cadmiumresponsive microRNAs in rice (Oryza sativa). J. Exp. Bot. 62, 3563-3573. doi: 10.1093/jxb/err046

Ding, Y., Ye, Y., Jiang, Z., Wang, Y., and Zhu, C. (2016). MicroRNA390 is involved in cadmium tolerance and accumulation in rice. Front. Plant Sci. 7:235. doi: $10.3389 /$ fpls.2016.00235

Evers, M., Huttner, M., Dueck, A., Meister, G., and Engelmann, J. C. (2015). miRA: adaptable novel miRNA identification in plants using small RNA sequencing data. BMC Bioinformatics 16:370. doi: 10.1186/s12859-015-0798-3

Fahlgren, N., Hill, S. T., Carrington, J. C., and Carbonell, A. (2016). P-SAMS: a web site for plant artificial microRNA and synthetic trans-acting small interfering RNA design. Bioinformatics 32, 157-158. doi: 10.1093/bioinformatics/btv534

Fang, Y., and Spector, D. L. (2007). Identification of nuclear dicing bodies containing proteins for microRNA biogenesis in living Arabidopsis plants. Curr. Biol. 17, 818-823. doi: 10.1016/j.cub.2007.04.005

Fischer, J. J., Beatty, P. H., Good, A. G., and Muench, D. G. (2013). Manipulation of microRNA expression to improve nitrogen use efficiency. Plant Sci. 210, 70-81. doi: 10.1016/j.plantsci.2013.05.009

Forieri, I., Wirtz, M., and Hell, R. (2013). Toward new perspectives on the interaction of iron and sulfur metabolism in plants. Front. Plant Sci. 4:357. doi: 10.3389/fpls.2013.00357

Gao, N., Qiang, X. M., Zhai, B. N., Min, J., and Shi, W. M. (2015). Transgenic tomato overexpressing ath-miR399d improves growth under abiotic stress conditions. Russ. J. Plant Physiol. 62, 360-366. doi: $10.1134 /$ S1021443715030061

Gao, P., Bai, X., Yang, L., Lv, D., Pan, X., Li, Y., et al. (2011). osa-MIR393: a salinity and alkaline stress-related microRNA gene. Mol. Biol. Rep. 38, 237-242. doi: 10.1007/s11033-010-0100-8

Gentile, A., Dias, L. I., Mattos, R. S., Ferreira, T. H., and Menossi, M. (2015). MicroRNAs and drought responses in sugarcane. Front. Plant Sci. 6:58. doi: 10.3389/fpls.2015.00058

Gielen, H., Remans, T., Vangronsveld, J., and Cuypers, A. (2012). MicroRNAs in metal stress: specific roles or secondary responses? Int. J. Mol. Sci. 13, 15826-15847. doi: 10.3390/ijms131215826

Gim, J. A., Ha, H. S., Ahn, K., Kim, D. S., and Kim, H. S. (2014). Genome-wide identification and classification of microRNAs derived from repetitive elements. Genomics Inform. 12, 261-267. doi: 10.5808/GI.2014. 12.4.261

Goswami, S., Kumar, R. R., and Rai, R. D. (2014). Heat-responsive microRNAs regulate the transcription factors and heat shock proteins in modulating thermo-stability of starch biosynthesis enzymes in wheat (Triticum aestivum L.) under the heat stress. Aust. J. Crop Sci. 8, 697-705.

Gregory, B. D., O’Malley, R. C., Lister, R., Urich, M. A., Tonti-Filippini, J., Chen, H., et al. (2008). A link between RNA metabolism and silencing affecting Arabidopsis development. Dev. Cell 14, 854-866. doi:10.1016/j.devcel.2008.04.005

Guan, Q., Lu, X., Zeng, H., Zhang, Y., and Zhu, J. (2013). Heat stress induction of miR398 triggers a regulatory loop that is critical for thermotolerance in Arabidopsis. Plant J. 74, 840-851. doi: 10.1111/tpj.12169 
Gupta, O. P., Sharma, P., Gupta, R. K., and Sharma, I. (2014). MicroRNA mediated regulation of metal toxicity in plants: present status and future perspectives. Plant Mol. Biol. 84, 1-18. doi: 10.1007/s11103-013-0120-6

Hackenberg, M., Gustafson, P., Langridge, P., and Shi, B. J. (2015). Differential expression of microRNAs and other small RNAs in barley between water and drought conditions. Plant Biotechnol. J. 13, 2-13. doi: 10.1111/pbi.12220

Hackenberg, M., Huang, P. J., Huang, C. Y., Shi, B. J., Gustafson, P., and Langridge, P. A. (2013). Comprehensive expression profile of microRNAs and other classes of non-coding small RNAs in barley under phosphorous-deficient and -sufficient conditions. DNA Res. 20, 109-125. doi: 10.1093/dnares/dss037

Hackenberg, M., Rodríguez-Ezpeleta, N., and Aransay, A. M. (2011). miRanalyzer: an update on the detection and analysis of microRNAs in high-throughput sequencing experiments. Nucleic Acids Res. 39, W132-W138. doi: $10.1093 / \mathrm{nar} / \mathrm{gkr} 247$

Hajyzadeh, M., Turktas, M., Khawar, K. M., and Unver, T. (2015). miR408 overexpression causes increased drought tolerance in chickpea. Gene 555, 186-193. doi: 10.1016/j.gene.2014.11.002

$\mathrm{He}, \mathrm{H}$., He, L., and Gu, M. (2014). Role of microRNAs in aluminum stress in plants. Plant Cell Rep. 33, 831-836. doi: 10.1007/s00299-014-1565-Z

Liu, H. H., Tian, X., Li, Y. J., Wu, C. A., and Zheng, C. C. (2008). Microarraybased analysis of stress-regulated microRNAs in Arabidopsis thaliana. RNA 14, 836-843. doi:10.1261/rna.895308

Hong, Y., and Jackson, S. (2015). Floral induction and flower formation- the role and potential applications of miRNAs. Plant Biotechnol. J. 13, 282-292. doi: 10.1111/pbi.12340

Hsu, S. D., Lin, F. M., Wu, W. Y., Liang, C., Huang, W. C., Chan, W. L., et al. (2011). miRTarBase: a database curates experimentally validated microRNA-target interactions. Nucleic Acids Res. 39, D163-D169. doi: 10.1093/nar/gkq1107

Hu, B., Zhu, C., Li, F., Tang, J., Wang, Y., Lin, A., et al. (2011). LEAF TIP NECROSIS1 plays a pivotal role in the regulation of multiple phosphate starvation responses in rice. Plant Physiol. 156, 1101-1115. doi: 10.1104/pp.110.170209

Huang, S. Q., Xiang, A. L., Che, L. L., Chen, S., Li, H., Song, J. B., et al. (2010). A set of miRNAs from Brassica napus in response to sulfate deficiency and cadmium stress. Plant Biotechnol. J. 8, 887-899. doi: 10.1111/j.1467-7652.2010.00517.x

Itaya, A., Bundschuh, R., Archual, A. J., Joung, J. G., Fei, Z., Dai, X., et al. (2007). Small RNAs in tomato fruit and leaf development. Biochim. Biophys. Acta 1779, 99-107. doi: 10.1016/j.bbagrm.2007.09.003

Jagadeeswaran, G., Li, Y. F., and Sunkar, R. (2014). Redox signaling mediates the expression of a sulfate-deprivation-inducible microRNA395 in Arabidopsis. Plant J. 77, 85-96. doi: 10.1111/tpj.12364

Jagadeeswaran, G., Zheng, Y., Sumathipala, N., Jiang, H., Arrese, E. L., Soulages, J. L., et al. (2010). Deep sequencing of small RNA libraries reveals dynamic regulation of conserved and novel microRNAs and microRNA-stars during silk worm development. BMC Genomics 11:52. doi: 10.1186/1471-2164-11-52

Jeong, D. H., and Green, P. J. (2013). The role of rice microRNAs in abiotic stress responses. J. Plant Biol. 56, 187-197. doi: 10.1007/s12374-013-0213-4

Jeong, D. H., Park, S., Zhai, J., Gurazada, S. G., De Paoli, E., Meyers, B. C., et al. (2011). Massive analysis of rice small RNAs: mechanistic implications of regulated microRNAs and variants for differential target RNA cleavage. Plant Cell 23, 4185-4207. doi: 10.1105/tpc.111.089045

Jha, A. B., and Dubey, R. S. (2004). Arsenic exposure alters activity behavior of key nitrogen assimilatory enzymes in growing rice plants. Plant Growth Regul. 43, 259-268. doi: 10.1023/B:GROW.0000045995.49365.df

Jin, Q., Xue, Z., Dong, C., Wang, Y., Chu, L., and Xu, Y. (2015). Identification and characterization of micrornas from tree peony (Paeonia ostii) and their response to copper stress. PLoS ONE 10:e0117584. doi: 10.1371/journal.pone.0117584

Jones-Rhoades, M. W., Bartel, D. P., and Bartel, B. (2006). MicroRNAs and their regulatory roles in plants. Annu. Rev. Plant Biol. 57, 19-53. doi: 10.1146/annurev.arplant.57.032905.105218

Kant, S., Peng, M., and Rothstein, S. J. (2011). Genetic regulation by NLA and microRNA827 for maintaining nitrate-dependent phosphate homeostasis in Arabidopsis. PLoS Genet. 7:e1002021. doi: 10.1371/journal.pgen.1002021

Kantar, M., Unver, T., and Budak, H. (2010). Regulation of barley miRNAs upon dehydration stress correlated with target gene expression. Funct. Integr. Genomics 10, 493-507. doi: 10.1007/s10142-010-0181-4
Kawashima, C. G., Matthewman, C. A., Huang, S., Lee, B. R., Yoshimoto, N., Koprivova, A., et al. (2011). Interplay of SLIM1 and miR395 in the regulation of sulfate assimilation in Arabidopsis. Plant J. 66, 863-876. doi: 10.1111/j.1365313X.2011.04547.X

Kawashima, C. G., Yoshimoto, N., Maruyama-Nakashita, A., Tsuchiya, Y. N., Saito, K., Takahashi, H., et al. (2009). Sulphur starvation induces the expression of microRNA-395 and one of its target genes but in different cell types. Plant J. 57, 313-321. doi: 10.1111/j.1365-313X.2008.03690.x

Kehr, J. (2013). Systemic regulation of mineral homeostasis by micro RNAs. Front. Plant Sci. 4:145. doi: 10.3389/fpls.2013.00145

Khan, G. A., Declerck, M., Sorin, C., Hartmann, C., Crespi, M., and LelandaisBrière, C. (2011). MicroRNAs as regulators of root development and architecture. Plant Mol. Biol. 77, 47-58. doi: 10.1007/s11103-011-9793-x

Khare, T., Kumar, V., and Kavi Kishor, P. B. (2015). $\mathrm{Na}^{+}$and $\mathrm{Cl}^{-}$ions show additive effects under $\mathrm{NaCl}$ stress on induction of oxidative stress and the responsive antioxidative defense in rice. Protoplasma 252, 1149-1165. doi: 10.1007/s00709-014-0749-2

Khraiwesh, B., Arif, M. A., Seumel, G. I., Ossowski, S., Weigel, D., Reski, R., et al. (2010). Transcriptional control of gene expression by microRNAs. Cell 140, 111-122. doi: 10.1016/j.cell.2009.12.023

Khraiwesh, B., Zhu, J. K., and Zhu, J. (2012). Role of miRNAs and siRNAs in biotic and abiotic stress responses of plants. Biochim. Biophys. Acta 1819, 137-148. doi: 10.1016/j.bbagrm.2011.05.001

Kozomara, A., and Griffiths-Jones, S. (2014). miRBase: annotating high confidence microRNAs using deep sequencing data. Nucleic Acids Res. 42, D68-D73. doi: 10.1093/nar/gkt1181

Kruszka, K., Pacak, A., Swida-Barteczka, A., Nuc, P., Alaba, S., Wroblewska, Z., et al. (2014). Transcriptionally and post-transcriptionally regulated microRNAs in heat stress response in barley. J. Exp. Bot. 65, 6123-6135. doi: $10.1093 /$ jxb/eru353

Kruszka, K., Pieczynski, M., Windels, D., Jarmolowski, A., Kulinsk, S. Z., and Vazquez, F. (2012). Role of microRNAs and other sRNAs of plants in their changing environments. J. Plant Physiol. 16, 1664-1672. doi: 10.1016/j.jplph.2012.03.009

Ku, Y. S., Wong, J. W. H., Mui, Z., Liu, X., Hui, J. H. L., Chan, T. F., et al. (2015). Small RNAs in plant responses to abiotic stresses: regulatory roles and study methods. Int. J. Mol. Sci. 16, 24532-24554. doi: 10.3390/ijms161024532

Kulcheski, F. R., Oliveira, L. F., Molina, L. G., Almerão, M. P., Rodrigues, F. A., Marcolino, J., et al. (2011). Identification of novel soybean microRNAs involved in abiotic and biotic stresses. BMC Genomics 12:307. doi: 10.1186/1471-2164$12-307$

Kumar, V., Shriram, V., Kavi Kishor, P. B., Jawali, N., and Shitole, M. G. (2010). Enhanced proline accumulation and salt stress tolerance of transgenic indica rice by over-expressing P5CSF129A gene. Plant Biotechnol. Rep. 4, 37-48. doi: 10.1007/S11816-009-0118-3

Kumar, V., Shriram, V., Nikam, T. D., Jawali, N., and Shitole, M. G. (2009). Antioxidant enzyme activities and protein profiling under salt stress in indica rice genotypes differing in salt tolerance. Arch. Agron. Soil Sci. 55, 379-394. doi: $10.1080 / 03650340802595543$

Laubinger, S., Sachsenberg, T., Zeller, G., Busch, W., Lohmann, J. U., Rätsch, G., et al. (2008). Dual roles of the nuclear cap-binding complex and SERRATE in pre-mRNA splicing and microRNA processing in Arabidopsis thaliana. Proc. Natl. Acad. Sci. U.S.A. 105, 8795-8800. doi: 10.1073/pnas.0802493105

Lee, R. C., Feinbaum, R. L., and Ambros, V. (1993). The C. elegans heterochronic gene lin-4 encodes small RNAs with antisense complementarity to lin-14. Cell $75,843-854$.

Lee, S. H., Li, C. W., Koh, K. W., Chuang, H. Y., Chen, Y. R., Lin, C. S., et al. (2014). MSRB7 reverses oxidation of GSTF2/3 to confer tolerance of Arabidopsis thaliana to oxidative stress. J. Exp. Bot. 65, 5049-5062. doi: 10.1093/jxb/eru270

Li, C., and Zhang, B. (2016). MicroRNAs in control of plant development. J. Cell. Physiol. 231, 303-313. doi: 10.1002/jcp.25125

Li, H., Deng, Y., Wu, T., Subramanian, S., and Yu, O. (2010). Misexpression of miR482, miR1512, and miR1515 increases soybean nodulation. Plant Physiol. 153, 1759-1770. doi: 10.1104/pp.110.156950

Li, H., Dong, Y., Yin, H., Wang, N., Yang, J., Liu, X., et al. (2011). Characterization of the stress associated microRNAs in Glycine max by deep sequencing. BMC Plant Biol. 11:170. doi: 10.1186/1471-2229-11-170 
Li, W., Wang, T., Zhang, Y., and Li, Y. (2016). Overexpression of soybean miR172c confers tolerance to water deficit and salt stress, but increases ABA sensitivity in transgenic Arabidopsis thaliana. J. Exp. Bot. 67, 175-194. doi: 10.1093/jxb/erv450

Li, Y., Zhang, Y., Shi, D., Liu, X., Qin, J., Ge, Q., et al. (2013). Spatial-temporal analysis of zinc homeostasis reveals the response mechanisms to acute zinc deficiency in Sorghum bicolor. New Phytol. 200, 1102-1115. doi: 10.1111/nph. 12434

Liang, G., Ai, Q., and Yu, D. (2015). Uncovering miRNAs involved in crosstalk between nutrient deficiencies in Arabidopsis. Sci. Rep. 5:11813. doi: $10.1038 /$ srep 11813

Liang, G., He, H., and Yu, D. (2012). Identification of nitrogen starvation responsive miRNAs in Arabidopsis thaliana. PLoS ONE 7:e48951. doi: 10.1371/journal.pone.0048951

Liang, G., Yang, F., and Yu, D. (2010). microRNA395 mediates regulation of sulfate accumulation and allocation in Arabidopsis thaliana. Plant J. 62, 1046-1057. doi: 10.1111/j.1365-313X.2010.04216.x

Licausi, F., Weits, D. A., Pant, B. D., Scheible, W.-R., Geigenberger, P., and van Dongen, J. T. (2011). Hypoxia responsive gene expression is mediated by various subsets of transcription factors and miRNAs that are determined by the actual oxygen availability. New Phytol. 190, 442-456. doi: 10.1111/j.14698137.2010.03451.x

Lin, C. C., Chen, Y. J., Chen, C. Y., Oyang, Y. J., Juan, H. F., and Huang, H. C. (2012). Crosstalk between transcription factors and microRNAs in human protein interaction network. BMC Syst. Biol. 6:18. doi: 10.1186/1752-0509-6-18

Liu, Q., and Zhang, H. (2012). Molecular identification and analysis of arsenite stress-responsive miRNAs in rice. J. Agric. Food Chem. 60, 6524-6536. doi: 10.1021/jf300724t

Llave, C., Xie, Z. X., Kasschau, K. D., and Carrington, J. C. (2002). Cleavage of Scarecrow-like mRNAtargets directed by a class of Arabidopsis miRNA. Science 297, 2053-2056. doi: 10.1126/science.1076311

Lundmark, M., Kørner, C. J., and Nielsen, T. H. (2010). Global analysis of microRNA in Arabidopsis in response to phosphate starvation as studied by locked nucleic acid-based microarrays. Physiol. Plant. 140, 57-68. doi: 10.1111/j.1399-3054.2010.01384.x

Lv, D. K., Bai, X., Li, Y., Ding, X. D., Ge, Y., Cai, H., et al. (2010). Profiling of cold-stress-responsive miRNAs in rice by microarrays. Gene 459, 39-47. doi: 10.1016/j.gene.2010.03.011

Ma, J. F., Shen, R., Nagao, S., and Tanimoto, E. (2004). Aluminum targets elongating cells by reducing cell wall extensibility in wheat roots. Plant Cell Physiol. 45, 583-589. doi: 10.1093/pcp/pch060

Mangrauthia, S. K., Agarwal, S., Sailaja, B., Madhav, M. S., and Voleti, S. R. (2013). "MicroRNAs and their role in salt stress response in plants" in Salt Stress in Plants, eds P. Ahmad, M. M. Azooz, and M. N. V. Prasad (New York, NY: Springer), 15-46.

Marín-González, E., and Suárez-López, P. (2012). “And yet it moves”: cell-to-cell and long-distance signaling by plant microRNAs. Plant Sci. 196, 18-30. doi: 10.1016/j.plantsci.2012.07.009

Meng, F., Liu, H., Wang, K., Liu, L., Wang, S., Zhao, Y., et al. (2013). Development associated microRNAs in grains of wheat (Triticum aestivum L.). BMC Plant Biol. 13:140. doi: 10.1186/1471-2229-13-140

Meng, J., Shi, G.-L., and Luan, Y.-S. (2016). Plant miRNA function prediction based on functional similarity network and transductive multi-label classification algorithm. Neurocomputing 179, 283-289. doi: 10.1016/j.neucom.2015.12.011

Meng, Y., Gou, L., Chen, D., Mao, C., Jin, Y., Wu, P., et al. (2011). PmiRKB: a plant microRNA knowledge base. Nucleic Acids Res. 39, D181-D187. doi: 10.1093/nar/gkq721

Mishra, A. K., Duraisamy, G. S., and Matoušek, J. (2015). Discovering microRNAs and their targets in plants. Crit. Rev. Plant Sci. 34, 553-571. doi: 10.1080/07352689.2015.1078614

Mittal, D., Sharma, N., Sharma, V., Sopory, S. K., and Sanan-Mishra, N. (2016). Role of microRNAs in rice plant under salt stress. Ann. Appl. Biol. 168, 2-18. doi: 10.1111/aab.12241

Moldovan, D., Spriggs, A., Yang, J., Pogson, B. J., Dennis, E. S., and Wilson, I. W. (2010). Hypoxia-responsive microRNAs and trans-acting small interfering RNAs in Arabidopsis. J. Exp. Bot. 61, 165-177. doi: 10.1093/jxb/ $\operatorname{erp} 296$
Moxon, S., Jing, R., Szittya, G., Schwach, F., Pilcher, R. L. R., Moulton, V., et al. (2008). Deep sequencing of tomato short RNAs identifies microRNAs targeting genes involved in fruit ripening. Genome Res. 18, 1602-1609. doi: 10.1101/gr.080127.108

Muñoz-Mérida, A., Perkins, J. R., Viguera, E., Thode, G., Bejarano, E. R., and Pérez-Pulido, A. J. (2012). Semirna: searching for plant miRNAs using target sequences. Omics 16, 168-177. doi: 10.1089/omi.2011.0115

Ni, Z., Hu, Z., Jiang, Q., and Zhang, H. (2012). Overexpression of gma-MIR394a confers tolerance to drought in transgenic Arabidopsis thaliana. Biochem. Biophys. Res. Commun. 427, 330-335. doi: 10.1016/j.bbrc.2012.09.055

Nischal, L., Mohsin, M., Khan, I., Kardam, H., Wadhwa, A., Abrol, Y. P., et al. (2012). Identification and comparative analysis of microRNAs associated with low-N tolerance in rice genotypes. PLoS ONE 7:e50261. doi: 10.1371/journal.pone.0050261

Numnark, S., Mhuantong, W., Ingsriswang, S., and Wichadakul, D. (2012). C- mii: a tool for plant miRNA and target identification. BMC Genomics 13:S16. doi: 10.1186/1471-2164-13-S7-S16

Pandey, R., Joshi, G., Bhardwaj, A. R., Agarwal, M., and Katiyar-Agarwal, S. (2014). A comprehensive genome-wide study on tissue-specific and abiotic stress-specific miRNAs in Triticum aestivum. PLoS ONE 9:e95800. doi: 10.1371/journal.pone.0095800

Patel, P., Ramachandruni, S. D., Kakrana, A., Nakano, M., and Meyers, B. C. (2016). miTRATA: a web-based tool for microRNA truncation and tailing analysis. Bioinformatics 32, 450-452 doi: 10.1093/bioinformatics/btv583

Paul, S., Datta, S. K., and Datta, K. (2015). miRNA regulation of nutrient homeostasis in plants. Front. Plant Sci. 6:232. doi: 10.3389/fpls.2015.00232

Pei, L., Jin, Z., Li, K., Yin, H., Wang, J., and Yang, A. (2013). Identification and comparative analysis of low phosphate tolerance associated microRNAs in two maize genotypes. Plant Physiol. Biochem. 70, 221-234. doi: 10.1016/j.plaphy.2013.05.043

Peng, T., Sun, H. Z., Du, Y. X., Zhang, J., Li, J. Z., Liu, Y. X., et al. (2013). Characterization and expression patterns of microRNAs involved in rice grain filling. PLoS ONE 8:e54148. doi: 10.1371/journal.pone.0054148

Privalle, L. S., Chen, J., Clapper, G., Hunst, P., Spiegelhalter, F., and Zhong, C. (2012). Development of an agricultural biotechnology crop product: testing from discovery to commercialization. J. Agric. Food Chem. 60, 10179-10187. doi: 10.1021/jf302706e

R Lorenzetti, A. P., A de Antonio, G. Y., Paschoal, A. R., and Domingues, D. S. (2016). PlanTE-MIR DB: a database for transposable element-related microRNAs in plant genomes. Funct. Integr. Genomics 16, 235-242. doi: 10.1007/s10142-016-0480-5

Rascio, N., and Navari-Izzo, F. (2011). Heavy metal hyperaccumulating plants: how and why do they do it? And what makes them so interesting? Plant Sci. 180, 169-181. doi: 10.1016/j.plantsci.2010.08.016

Reinhart, B. J., Weinstein, E. G., Rhoades, M. W., Bartel, B., and Bartel, D. P. (2002). MicroRNAs in plants. Genes Dev. 16, 1616-1626. doi: $10.1101 / \mathrm{gad} .1004402$

Remita, M. A., Lord, E., Agharbaoui, Z., Leclercq, M., Badawi, M., Makarenkov, V., et al. (2015). WMP: a novel comprehensive wheat miRNA database, including related bioinformatics software. BioRxiv 024893. doi: 10.1101/024893

Requejo, R., and Tena, M. (2005). Proteome analysis of maize roots reveals that oxidative stress is a main contributing factor to plant arsenic toxicity. Phytochemistry 66, 1519-1528. doi: 10.1016/j.phytochem.2005.05.003

Rhee, S., Chae, H., and Kim, S. (2015). PlantMirnaT: miRNA and mRNA integrated analysis fully utilizing characteristics of plant sequencing data. Methods 83, 80-87. doi: 10.1016/j.ymeth.2015.04.003

Ripoll, J. J., Bailey, L. J., Mai, Q. A., Wu, S. L., Hon, C. T., Chapman, E. J., et al. (2015). microRNA regulation of fruit growth. Nat. Plants 1, 15036. doi:10.1038/nplants.2015.36

Rizwan, M., Ali, S., Adrees, M., Rizvi, H., Zia-ur-Rehman, M., Hannan, F., et al. (2016). Cadmium stress in rice: toxic effects, tolerance mechanisms, and management: a critical review. Environ. Sci. Pollut. Res. Int. doi: 10.1007/s11356-016-6436-4. [Epub ahead of print].

Rong, W., Qi, L., Wang, A., Ye, X., Du, L., Liang, H., et al. (2014). The ERF transcription factor TaERF3 promotes tolerance to salt and drought stresses in wheat. Plant Biotechnol. J. 12, 468-479. doi: 10.1111/pbi.12153

Rosewick, N., Durkin, K., Momont, M., Takeda, H., Caiment, F., Cleuter, Y., et al. (2013). ST105 Deep sequencing reveals abundant Pol III retroviral microRNA 
cluster in Bovine Leukemia Virus-induced leukemia. J. Acq. Imm. Def. Syndr. 62, 66. doi: 10.1097/01.qai.0000429267.82844.b6

Rueda, A., Barturen, G., Lebrón, R., Gómez-Martín, C., Alganza, Á., Oliver, J. L., et al. (2015). sRNAtoolbox: an integrated collection of small RNA research tools. Nucleic Acids Res. 43, W467-W473. doi: 10.1093/nar/gkv555

Silva, S. (2012). Aluminium toxicity targets in plants. J. Bot. 2012:219462. doi: $10.1155 / 2012 / 219462$

Song, J. B., Gao, S., Wang, Y., Li, B. W., Zhang, Y. L., and Yang, Z. M. (2016). miR394 and its target gene LCR are involved in cold stress response in Arabidopsis. Plant Gene 5, 56-64. doi: 10.1016/j.plgene.2015.12.001

Srivastava, S., Srivastava, A. K., Suprasanna, P., and D'Souza, S. F. (2009). Comparative biochemical and transcriptional profiling of two contrasting varieties of Brassica juncea $\mathrm{L}$. in response to arsenic exposure reveals mechanisms of stress perception and tolerance. J. Exp. Bot. 60, 3419-3431. doi: 10.1093/jxb/erp181

Srivastava, S., Srivastava, A. K., Suprasanna, P., and D'Souza, S. F. (2012). Identification and profiling of arsenic stress-induced microRNAs in Brassica juncea. J. Exp. Bot. 64, 303-315. doi: 10.1093/jxb/ers333

Srivastava, S., Suprasanna, P., and D'Souza, S. F. (2011). Mechanisms of arsenic tolerance and detoxification in plants and their application in transgenic technology: a critical appraisal. Int. J. Phytoremed. 14, 506-517. doi: $10.1080 / 15226514.2011 .604690$

Sun, G. (2012). MicroRNAs and their diverse functions in plants. Plant Mol. Biol. 80, 17-36. doi:10.1007/s11103-011-9817-6

Sun, X., Dong, B., Yin, L., Zhang, R., Du, W., Liu, D., et al. (2013). PMTED: a plant microRNA target expression database. BMC Bioinformatics 14:174. doi: 10.1186/1471-2105-14-174

Sun, X., Xu, L., Wang, Y., Yu, R., Zhu, X., Luo, X., et al. (2015). Identification of novel and salt-responsive miRNAs to explore miRNA-mediated regulatory network of salt stress response in radish (Raphanus sativus L.). BMC Genomics 16:197. doi: 10.1186/s12864-015-1416-5

Sunkar, R., Kapoor, A., and Zhu, J. K. (2006). Posttranscriptional induction of two $\mathrm{Cu} / \mathrm{Zn}$ superoxide dismutase genes in Arabidopsis is mediated by downregulation of miR398 and important for oxidative stress tolerance. Plant Cell 18, 2051-2065. doi: 10.1105/tpc.106.041673

Sunkar, R., Li, Y. F., and Jagadeeswaran, G. (2012). Functions of microRNAs in plant stress responses. Trends Plant Sci. 17, 196-203. doi:10.1016/j.tplants.2012.01.010

Szczesniak, M. W., Deorowicz, S., Gapski, J., Kaczyñski, £., and Makałowska, I. (2011). miRNEST database: an integrative approach in microRNA search and annotation. Nucleic Acids Res. 40, D198-D204. doi: 10.1093/nar/gkr1159

Tripathi, A., Goswami, K., and Sanan-Mishra, N. (2015). Role of bioinformatics in establishing microRNAs as modulators of abiotic stress responses: the new revolution. Front. Physiol. 6:286. doi: 10.3389/fphys.2015.00286

Turan, S., and Tripathy, B. C. (2013). Salt and genotype impact on antioxidative enzymes and lipid peroxidation in two rice cultivars during de-etiolation. Protoplasma 250, 209-222. doi:10.1007/s00709-012-0395-5

Valdés-López, O., Yang, S. S., Aparicio-Fabre, R., Graham, P. H., Reyes, J. L., Vance, C. P., et al. (2010). MicroRNA expression profile in common bean (Phaseolus vulgaris) under nutrient deficiency stresses and manganese toxicity. New Phytol. 187, 805-818. doi: 10.1111/j.1469-8137.2010.03320.x

Voinnet, O. (2009). Origin, biogenesis, and activity of plant microRNAs. Cell 136, 669-687. doi: 10.1016/j.cell.2009.01.046

Wang, B., Sun, Y. F., Song, N., Wang, X. J., Feng, H., Huang, L. L., et al. (2013). Identification of UV-B-induced microRNAs in wheat. Genet. Mol. Res. 12, 4213-4221. doi: 10.4238/2013

Wang, C., Huang, W., Ying, Y., Li, S., Secco, D., Tyerman, S., et al. (2012). Functional characterization of the rice SPX-MFS family reveals a key role of OsSPX-MFS1 in controlling phosphate homeostasis in leaves. New Phytol. 196, 139-148. doi: 10.1111/j.1469-8137.2012.04227.x

Wang, F., Polydore, S., and Axtell, M. J. (2015). More than meets the eye? Factors that affect target selection by plant miRNAs and heterochromatic siRNAs. Curr. Opin. Plant Biol. 27, 118-124. doi: 10.1016/j.pbi.2015.06.012

Wani, S. H., Sah, S. K., Hussain, M. A., Kumar, V., and Balachandra, S. M. (2016). "Transgenic approaches for abiotic stress tolerance in crop plants," in Advances in Plant Breeding Strategies, Vol. 2 Agronomic, Abiotic and Biotic Stress Traits, eds J. M. Al-Khayri, S. M. Jain, and D. V. Johnson (Gewerbestrasse: Springer International), 345-396.
Waters, B. M., Mcinturf, S. A., and Stein, R. J. (2012). Rosette iron deficiency transcript and microRNA profiling reveals links between copper and iron homeostasis in Arabidopsis thaliana. J. Exp. Bot. 63, 5903-5918. doi: $10.1093 / \mathrm{jxb} / \mathrm{ers} 239$

Wu, J., Liu, Q., Wang, X., Zheng, J., Wang, T., You, M., et al. (2013). mirTools 2.0 for non-coding RNA discovery, profiling, and functional annotation based on high-throughput sequencing. RNA Biol. 10, 1087-1092. doi: 10.4161/rna.25193

Wu, L., Zhou, H., Zhang, Q., Zhang, J., Ni, F., Liu, C., et al. (2010). DNA methylation mediated by a microRNAs pathway. Mol. Cell. 38, 465-475. doi: 10.1016/j.molcel.2010.03.008

Xia, K., Wang, R., Ou, X., Fang, Z., Tian, C., Duan, J., et al. (2012). OsTIR1 and OsAFB2 downregulation via OsmiR393 overexpression leads to more tillers, early flowering and less tolerance to salt and drought in rice. PLOS ONE 7:e30039. doi: 10.1371/journal.pone.0030039

Xie, F., Jones, D. C., Wang, Q., Sun, R., and Zhang, B. (2015). Small RNA sequencing identifies miRNA roles in ovule and fibre development. Plant Biotechnol. J. 13, 355-369. doi: 10.1111/pbi.12296

Xin, M., Wang, Y., Yao, Y., Song, N., Hu, Z., Qin, D., et al. (2011). Identification and characterization of wheat long non-protein coding RNAs responsive to powdery mildew infection and heat stress by using microarray analysis and SBS sequencing. BMC Plant Biol. 11:61. doi: 10.1186/1471-2229-11-61

Xin, M., Wang, Y., Yao, Y., Xie, C., Peng, H., Ni, Z., et al. (2010). Diverse set of microRNAs are responsive to powdery mildew infection and heat stress in wheat (Triticum aestivum L.). BMC Plant Biol. 10:123. doi: 10.1186/1471-2229$10-123$

Xu, L., Wang, Y., Zhai, L., Xu, Y., Wang, L., Zhu, X., et al. (2013). Genomewide identification and characterization of cadmium-responsive microRNAs and their target genes in radish (Raphanus sativus L.) roots. J. Exp. Bot. 64, 4271-4287. doi: 10.1093/jxb/ert240

Yang, C., Li, D., Mao, D., Liu, X. U. E., Ji, C., Li, X., et al. (2013). Overexpression of microRNA319 impacts leaf morphogenesis and leads to enhanced cold tolerance in rice (Oryza sativa L.). Plant Cell Environ. 36, 2207-2218. doi: $10.1111 /$ pce. 12130

Yang, X., and Li, L. (2011). miRDeep-P: a computational tool for analyzing the microRNA transcriptome in plants. Bioinformatics 27, 2614-2615. doi: 10.1093/bioinformatics/btr430

Yang, X., Wang, L., Yuan, D., Lindsey, K., and Zhang, X. (2013). Small RNA and degradome sequencing reveal complex miRNA regulation during cotton somatic embryogenesis. J. Exp. Bot. 64, 1521-1536. doi: 10.1093/jxb/ert013

Yang, Z. M., and Chen, J. (2013). A potential role of microRNAs in regulating plant response to metal toxicity. Metallomics 5, 1184-1190. doi: 10.1039/c3mt0 0022b

Yi, X., Zhang, Z., Ling, Y., Xu, W., and Su, Z. (2015). PNRD: a plant non-coding RNA database. Nucleic Acids Res. 43, D982-D989. doi: 10.1093/nar/gku1162

Yu, L. J., Luo, Y. F., Liao, B., Xie, L. J., Chen, L., Xiao, S., et al. (2012). Comparative transcriptome analysis of transporters, phytohormone and lipid metabolism pathways in response to arsenic stress in rice (Oryza sativa). New Phytol. 195, 97-112. doi: 10.1111/j.1469-8137.2012.04154.x

Zeller, G., Henz, S. R., Widmer, C. K., Sachsenberg, T., Rätsch, G., Weigel, D., et al. (2009). Stress-induced changes in the Arabidopsis thaliana transcriptome analyzed using whole-genome tiling arrays. Plant J. 58, 1068-1082. doi: 10.1111/j.1365-313X.2009.03835.x

Zeng, Q. Y., Yang, C. Y., Ma, Q. B., Li, X. P., Dong, W. W., and Nian, H. (2012). Identification of wild soybean miRNAs and their target genes responsive to aluminum stress. BMC Plant Biol. 12:182. doi: 10.1186/1471-2229-12-182

Zhai, L., Liu, Z., Zou, X., Jiang, Y., Qiu, F., Zheng, Y., et al. (2013). Genomewide identification and analysis of microRNA responding to long-term waterlogging in crown roots of maize seedlings. Physiol. Plant. 147, 181-193. doi: $10.1111 / j .1399-3054.2012 .01653 . x$

Zhang, B. (2015). MicroRNA: a new target for improving plant tolerance to abiotic stress. J. Exp. Bot. 66, 1749-1761. doi: 10.1093/jxb/erv013

Zhang, B., and Wang, Q. (2015). MicroRNA-Based Biotechnology for Plant Improvement. J Cell Physiol. 230, 1-15. doi: 10.1002/jcp.24685

Zhang, B., and Wang, Q. (2016). MicroRNA, a new target for engineering new crop varieties. Bioengineered 7, 7-10. doi: 10.1080/21655979.2016.1141838

Zhang, S., Yue, Y., Sheng, L., Wu, Y., Fan, G., Li, A., et al. (2013). PASmiR: a literature-curated database form iRNA molecular regulation in plant response to abiotic stress. BMC Plant Biol. 13:33. doi:10.1186/1471-2229-13-33 
Zhang, Y., Zhu, X., Chen, X., Song, C., Zou, Z., Wang, Y., et al. (2014a). Identification and characterization of cold-responsive microRNAs in tea plant (Camellia sinensis) and their targets using high-throughput sequencing and degradome analysis. BMC Plant Biol. 14:271. doi: 10.1186/s12870-0140271-x

Zhang, Z., Jiang, L., Wang, J., and Chen, M. (2014b). MTide: an integrated tool for the identification of miRNA-target interaction in plants. Bioinformatics 31, 290-291. doi: 10.1093/bioinformatics/btu633

Zhang, Z., Yu, J., Li, D., Zhang, Z., Liu, F., Zhou, X., et al. (2010). PMRD: plant microRNA database. Nucleic Acids Res. 38, D806-D813. doi: 10.1093/nar/gkp818

Zhao, B., Liang, R., Ge, L., Li, W., Xiao, H., Lin, H., et al. (2007). Identification of drought-induced microRNAs in rice. Biochem. Biophys. Res. Commun. 354, 585-590. doi: 10.1016/j.bbrc.2007.01.022

Zhao, X., Ding, C., Chen, L., Wang, S., Wang, Q., and Ding, Y. (2012). Comparative proteomic analysis of the effects of nitric oxide on alleviating Cd-induced toxicity in rice (Oryza sativa L.). Plant Omics 5, 604-614.

Zhao, X., Liu, X., Guo, C., Gu, J., and Xiao, K. (2013). Identification and characterization of microRNAs from wheat (Triticum aestivum L.) under phosphorus deprivation. J. Plant Biochem. Biotechnol. 22, 113-123. doi: 10.1007/s13562-012-0117-2

Zhou, L., Liu, Y., Liu, Z., Kong, D., Duan, M., and Luo, L. (2010). Genome-wide identification and analysis of drought-responsive microRNAs in Oryza sativa. J. Exp. Bot. 61, 4157-4168. doi: 10.1093/jxb/erq237

Zhou, M., Li, D. Y., Li, Z. G., Hu, Q., Yang, C. H., Zhu, L. H., et al. (2013). Constitutive expression of a miR319 gene alters plant development and enhances salt and drought tolerance in transgenic creeping bentgrass. Plant Physiol. 161, 1375-1391. doi: 10.1104/pp.112.208702

Zhou, M., and Luo, H. (2013). MicroRNA-mediated gene regulation: potential application for plant genetic engineering. Plant Mol. Biol. 83, 59-75. doi: 10.1007/s11103-013-0089-1

Zhou, Z. S., Song, J. B., and Yang, Z. M. (2012a). Genome-wide identification of Brassica napus microRNA and their targets in response to cadmium. J. Exp. Bot. 63, 4597-4613. doi: 10.1093/jxb/ers136

Zhou, Z. S., Wang, S. J., and Yang, Z. M. (2008). Biological detection and analysis of mercury toxicity to alfalfa (Medicago sativa) plants. Chemosphere 70, 1500-1509. doi: 10.1016/j.envexpbot.2008.06.001

Zhou, Z. S., Zeng, H. Q., Liu, Z. P., and Yang, Z. M. (2012b). Genome-wide identification of Medicago truncatula microRNAs and their targets reveals their differential regulation by heavy metal. Plant Cell Environ. 35, 86-99. doi: 10.1111/j.1365-3040.2011.02418.x

Conflict of Interest Statement: The authors declare that the research was conducted in the absence of any commercial or financial relationships that could be construed as a potential conflict of interest.

Copyright (c) 2016 Shriram, Kumar, Devarumath, Khare and Wani. This is an openaccess article distributed under the terms of the Creative Commons Attribution License (CC BY). The use, distribution or reproduction in other forums is permitted, provided the original author(s) or licensor are credited and that the original publication in this journal is cited, in accordance with accepted academic practice. No use, distribution or reproduction is permitted which does not comply with these terms. 